\title{
Studies of polycyanurates based on phenoxy-substituted cyclic phosphazenes: synthesis of the monomer and a preliminary study of its thermal properties in binary blends
}

\author{
Ian Hamerton* ${ }^{1}$, Simon Glynn ${ }^{1}$, John N. Hay ${ }^{1}$, Mark A. Pullinger ${ }^{1}$ and Stephen J. \\ Shaw $^{2}$
}

${ }^{1}$ Chemical Sciences Division, Faculty of Health and Medical Sciences, University of Surrey, Guildford, Surrey, GU2 7XH, U.K.

${ }^{2}$ Dstl, Porton Down, Salisbury, Wiltshire, SP4 OJQ, U.K.

* Correspondence to: Ian Hamerton, Chemical Sciences Division, Faculty of Health and Medical Sciences, University of Surrey, Guildford, Surrey, GU2 7XH, U.K. E-mail: i.hamerton@surrey.ac.uk

\begin{abstract}
The four-step preparation of a new monomer, 1,2,3-tris(4-cyanatophenoxy)-,3',5,5-tris-phenoxy$2 \lambda^{5}, 4 \lambda^{5}, 6 \lambda^{5}-[1,3,5,2,4,6]$-triazatriphosphinine, is reported. Characterization of the monomer is undertaken using spectroscopic and chromatographic methods and elemental analysis and the data are in agreement with the proposed structure (as a mixture of isomers). The thermal polymerization of the monomer and its behaviour within selected blends containing 2,2-bis(4cyanatophenyl)propane (AroCy B10) are studied using differential scanning calorimetry. The blends appear to melt sharply at $c a .80^{\circ} \mathrm{C}$ onset of polymerization (corresponding to the melting point of the commercial dicyanate) before commencing polymerization directly thereafter. Typical exothermic peak maxima at $c a .135^{\circ} \mathrm{C}$ are observed, whilst the cure is apparently concluded by $200^{\circ} \mathrm{C}$ under the scanning conditions. On rescan, the cured samples display glass transition values
\end{abstract}


in the region of $160-190^{\circ} \mathrm{C}$, depending on composition with the higher values reflecting increasing amounts of the new material. The cured polycyanurate of the tricyclophosphazene is also analysed using thermogravimetric analysis and displays a mass loss of $5 \%$ at approximately $381^{\circ} \mathrm{C}$ in air and $366^{\circ} \mathrm{C}$ in nitrogen. When 1,2,3-tris(4-cyanatophenoxy)-, 3',5,5-tris-phenoxy- $2 \lambda^{5}, 4 \lambda^{5}, 6 \lambda^{5}$ $[1,3,5,2,4,6]$-triazatriphosphinine is combined with AroCy B10, the cured copolymers (containing between 10 and $30 \mathrm{wt} \%$ of the tricyclophosphazene) show disappointing thermal stability with a progressive reduction in the onset of degradation with increasing phosphazine content; this may be a result of incomplete cure.

\section{Author Keywords: cyanate esters, cyclophosphazenes, synthesis, thermal stability.}

\section{Introduction}

Cyanate ester (CE) resins are currently used widely in microelectronic applications, especially as dielectric substrates, due in part to the fine combination of their high dimensional stability, low dielectric constants (typically around $2.7-3$ at $25^{\circ} \mathrm{C}$ and $1 \mathrm{MHz}$ ) and perhaps more importantly their low dielectric loss properties. For example dissipation factors as low as $1 \times 10^{-3}$ (at $1 \mathrm{MHz}$ ) and $2 \times$ $10^{-3}$ (at $1 \mathrm{GHz}$ ) can be achieved using commercial resins [1]. In routine use in these technological applications, low flammability and heat resistance is desirable, but often found to be lacking in common commodity polymers. Consequently, the use of increasingly exotic materials is common in apparently mundane consumer goods [2]. The use of brominated additives in epoxy and bismaleimide resins is well documented [3] and aryl cyanate esters may also be flame retarded in this manner, although a much lower level of bromine is required to achieve a UL94 V-0 rating (in Underwriters Laboratories ignition tests) [4]. Similarly, if brominated epoxy resins (e.g. the tetrabromodiglycidyl ether of bisphenol A) are employed in epoxy/CE blends, then ca. $12 \%$ bromine is required to yield an FR material, compared with ca. 20\% in corresponding epoxy resins. However, while generally efficacious, the use of brominated additives or monomers does hold 
inherent disadvantages: the potential to corrode metal components (via the generation of halide ions in warm, humid environments); depression of glass transition temperature $\left(\mathrm{T}_{\mathrm{g}}\right)$; elevation of dielectric loss properties and increasing the cured resin density. Other resin performance parameters can be affected: the modification of AroCy B with 25\% brominated epoxy was reported [5] to result in a reduction in thermo-oxidative stability, with the onset of degradation falling from $411^{\circ} \mathrm{C}$ to $285^{\circ} \mathrm{C}$ under identical analysis conditions.

A further, serious disadvantage of halogen compounds in this manner arises from the toxicity of the hydrogen halide (in this case $\mathrm{HBr}$ ) formed during combustion and this, together with some fears over other hazardous combustion products has prompted recent legislation in some parts of the globe to reduce society's general reliance on halogenated FRs. For example, the EC has proposed to restrict the use of brominated diphenyl oxide FRs, due to the observation that highly toxic and potentially carcinogenic brominated furans may form during combustion [6]. The World Health Organization and the US Environmental Protection Agency also recommend exposure limit and risk assessment of dioxins and similar compounds [7,8]. Consequently, increasing effort is being directed towards the development of FR additives or inherently flame retardant materials that do not rely on halogens for their operation [9].

The development of inherently self-extinguishing CE monomers is attractive: the traditional use of hydrated alumina $\left(\mathrm{Al}_{2} \mathrm{O}_{3} \cdot 3 \mathrm{H}_{2} \mathrm{O}\right)$ is not appropriate in this case since the evolution of water to cool (endothermically) the pyrolysis zone actually promotes hydrolysis and hence enhances degradation. Thus, replacement of the isopropyl bridge in AroCy B with sulphur (in the erstwhile commercial monomer, AroCy T) or perfluorination (in the form of AroCy F) not only leads to the production of UL94 V-0 rated CE resins, but can also to reactive additives that can improve, through blending, the fire resistance of CEs to UL94 V-0, depending on composition, for certain materials for thermallysensitive components. Lyon et al. [10,11] examined the combustibility of (largely commercial) 
polycyanurates derived from a variety of cyanate ester monomers in an attempt to correlate the chemical structure of these materials with their fire behaviour (e.g. ignition characteristics, burning behaviour, and combustion efficiency in the flame). Thus, the halogen-containing polycyanurates were difficult to ignite and had extremely low heat release rates, while soot production and carbon monoxide yields were comparable to, or lower than, hydrocarbon-based materials. They found that, excluding the halogen-containing polycyanurates, the net heats of combustion fell within the relatively narrow range $28.6-34.4 \mathrm{~kJ} \mathrm{~g}^{-1}$.

The use of phosphorus to impart flame resistance has an established history and cyclotriphosphazenes with skeletal nitrogen and phosphorus atoms are flame retardant and selfextinguishing [12] and when incorporated into thermoset networks or into the chain structure of thermoplastics, they can increase the thermal and flame resistance of these polymers. Examples of this approach include polyfunctional cyclotriphosphazenes bearing e.g. epoxy groups [13], primary amines [14] or, more pertinently, cyanato groups [15]. In the latter study, Nair et al. reported the preparation of cyclotriphosphazenes from hexachlorotriphospahzene and monosodium salts of bisphenol A using a relatively inconvenient preparative route (e.g. initial reaction with finely dispersed sodium particles in boiling toluene) to yield a mixture of products. Nair et al. found that the corresponding triazines underwent thermal decomposition (under nitrogen) at $c a .450{ }^{\circ} \mathrm{C}$, some $20 \mathrm{~K}$ higher than the bisphenol A analogue, with char residues of $50-60 \%$ at $700{ }^{\circ} \mathrm{C}(c f .40 \%$ for the bisphenol analogue). The glass transitions of the cured polycyanurates were reported to fall in the range $160-175^{\circ} \mathrm{C}$ with LOI values of 35 and $38 \%$, raised slightly from $32 \%$ for the polymer of bisphenol A dicyanate.

The rationale for the current work was to produce inherently flame retardant phosphorus-containing cyanate ester monomers, using a relatively facile route, which could be used to form copolymers with commercial cyanate monomers or other high temperature monomers, such as epoxy resins. 
This paper details the preparative steps involved, the characterization data and the preliminary thermal analysis data.

\section{Results and Discussion}

\subsection{Synthesis and characterization}

The synthesis of the partially-protected chlorinated cyclotriphosphazene (1) was carried out by mixing together an aqueous solution of phenol and sodium hydroxide with a solution of hexachlorocyclotriphosphazene and tri-n-butylhexadecylphosphonium bromide in dichloromethane (Scheme 1). A mixture of three products (as evidenced by TLC, $n$-heptane: dichloromethane, 70:30) was obtained as highly viscous, colourless oil and this was initially assumed to comprise the tri-, tetra- and penta-phenoxy-substituted cyclotriphosphazenes (for despite maintaining strict stoichiometry a statistical mixture would inevitably result). As the $\mathrm{R}_{\mathrm{f}}$ of the starting material, hexachlorocyclotriphosphazene, was much greater than the components of the mixture it was possible to conclude that the mixture contained none of this starting material.

Flash chromatography proved a useful method to isolate the different fractions, but owing to the viscosity of the product, it proved very difficult to add the oil directly to the head of the column and so the product was dissolved in a minimum of eluent and then added to the column. The limited solubility of the oil initially necessitated the use of relatively large volumes of solvent to transfer the material to the column and several mixed fractions were obtained as a result, which may account for the lower yield compared with the literature (78 \%) [16]. An alternative strategy was adopted during the analysis of the scaled up procedure and the oil was pre-adsorbed on to a small quantity of silica, prior to addition of this to the head of the column. Incidentally, the efficiency of the reaction might also have been improved by changing the catalyst for, while tri-n-butylhexadecylphosphonium bromide was chosen on the basis of its ready availability, methyldialkylammonium bromides ("alkyl" 
being perhaps $n$-octyl) were cited [16] as being the most efficient of those studied. The synthesis of the phenoxy-substituted derivative (1) was a relatively facile reaction to perform, yielding ca. $65 \%$ and it was decided to scale up the reaction. This was accomplished relatively easily and a $10 \mathrm{~g}$ scale preparation produced a higher (75\%) yield, while $25 \mathrm{~g}$ scale yielded ca. $51 \%$.

\section{Scheme 1. Schematic showing the preparation of compound (1)}

In order to identify the nature of the components $(1 \mathrm{~A}$ and $1 \mathrm{~B})$ in the reaction mixture, ${ }^{31} \mathrm{P}$ NMR was employed. The starting material, hexachlorocyclotriphosphazene, displays a single chemical shift and this was in agreement with published assignments wherein values of 20-24 ppm were attributed to a phosphorus nucleus in this environment [15]. Infrared analysis demonstrated a significant stretching band at $1217 \mathrm{~cm}^{-1}$ consistent with the presence of $\mathrm{P}-\mathrm{Cl}$ bonds. Infrared analysis of (1A) (Figure 1) showed principal bands at $1590 \mathrm{~cm}^{-1}$ and $1488 \mathrm{~cm}^{-1}$ (aromatic quadrant stretching), 1263 $\mathrm{cm}^{-1}$ (P-OPh stretch), $1235 \mathrm{~cm}^{-1}$ (P-Cl stretch), $766 \mathrm{~cm}^{-1}$ and $688 \mathrm{~cm}^{-1}$ (Ar-H out of plane bends).

\section{Figure 1. FTIR transmission spectrum of compound (1A) - vertical scale (\%)}

These data support the structure having some chlorine atoms substituted by phenoxy groups (as evidenced by the aromatic bands). The $\mathrm{P}-\mathrm{Cl}$ bands and a band attributed to $\mathrm{P}-\mathrm{OPh}$ were in agreement with the literature [17].

Component 1A yielded a ${ }^{31} \mathrm{P}$ NMR spectrum with shifts at 20-21 ppm $\left[\mathrm{N}=\mathrm{P}(\mathrm{Cl})_{2}\right], 18.6-19.0 \mathrm{ppm}$ $[\mathrm{N}=\mathrm{P}(\mathrm{Cl})(\mathrm{OPh})]$ and 4.47-5.97 $\mathrm{ppm}\left[\mathrm{N}=\mathrm{P}(\mathrm{OPh})_{2}\right]$. By drawing each possible structure arising from the different possible substitution patterns, it was possible to predict, on the basis of the degree of substitution, symmetry and coupling, the ${ }^{31} \mathrm{P}$ NMR spectra that should result. Owing to the very low relative intensity of the shifts observed around $18 \mathrm{ppm}$, it was decided that component (1A) 
contained mainly $\left[\mathrm{N}=\mathrm{P}(\mathrm{Cl})_{2}\right]$ and $\left[\mathrm{N}=\mathrm{P}(\mathrm{OPh})_{2}\right]$ substitution patterns with the likely structure shown in Scheme 2.

Scheme 2. Representative structures present in fractions (1A) and (1B)

The predicted ${ }^{31} \mathrm{P}$ NMR spectrum suggests a triplet at around $5 \mathrm{ppm}\left[\mathrm{N}=\mathrm{P}(\mathrm{OPh})_{2}\right]$, due to coupling with two $\left[\mathrm{N}=\mathrm{P}(\mathrm{Cl})_{2}\right]$ groups, as well as a doublet at around $20 \mathrm{ppm}\left[\mathrm{N}=\mathrm{P}(\mathrm{Cl})_{2}\right]$, due to coupling with one $\left[\mathrm{N}=\mathrm{P}(\mathrm{OPh})_{2}\right]$ group. The empirical spectrum is shown in Figure 2. The actual sample is likely to contain a statistical distribution of isomers (e.g. with traces of $[\mathrm{N}=\mathrm{P}(\mathrm{Cl})(\mathrm{OPh})])$ with the aforementioned structure predominant. A ${ }^{1} \mathrm{H}$ NMR spectrum of the aromatic region is shown in Figure 3 (upper): the complexity of the pattern resulting from the distribution of phenoxy substituents around the cyclotriphosphazene core.

The ${ }^{31} \mathrm{P}$ NMR spectrum of (1B) showed evidence of a different distribution of products: a triplet at 20 ppm due to coupling with one $\left[\mathrm{N}=\mathrm{P}(\mathrm{Cl})_{2}\right]$ group and a doublet at around 5-7 ppm, due to coupling with one $\left[\mathrm{N}=\mathrm{P}(\mathrm{OPh})_{2}\right]$ group. This suggests that $(1 \mathrm{~B})$ is predominantly represented by the structure shown above. The empirical spectrum is shown in Figure 4. Although the spectrum looks quite complex, closer inspection reveals that the shifts between 18-21 ppm and 4-6 ppm are actually due to a small amount of component (1A) remaining in component (1B).

The corresponding ${ }^{1} \mathrm{H}$ NMR spectrum of the aromatic region of component (1B) is shown in Figure 3 (lower). There are distinct differences in substitution pattern demonstrating the variation in isomeric distribution. In view of the fact that component (1B) was only a minor (and differentlysubstituted) component, it was decided to select only (1A) for the next step of the synthesis and for convenience, subsequent molar calculations for reagents were based on this structure (i.e. each compound was assumed on average to bear three chlorine atoms). 
Figure 2. ${ }^{31} \mathrm{P}$ NMR spectrum (in $\mathrm{CDCl}_{3}$ ) of compound (1A)

Figure 3. ${ }^{1} \mathrm{H}$ NMR spectra (in $\mathrm{CDCl}_{3}$ ) showing aromatic region of compound (1A) (above) and compound (1B) (below) - note spectra are not plotted on common axes.

Figure 4. ${ }^{31} \mathrm{P}$ NMR spectrum (in $\mathrm{CDCl}_{3}$ ) of compound (1B)

Scheme 3. Preparation of compound (2) showing the predominant isomer

The preparation of (2) was based on a reported procedure [18], but modified to accommodate these reagents. The use of 4-methoxyphenol groups prevents further chain extension via condensation and these are cleaved using acid hydrolysis during the next step to produce the hydroxy precursor (3). The blocked cyclotriphosphazene compound (1A), 4-methoxyphenol and potassium carbonate were dissolved in DMAc and heated to reflux and monitored using TLC. During reflux, the colour of the mixture changed from pale straw to light pink indicating a change in the degree of conjugation within the molecule, consistent with the increased aromaticity arising from the phenoxy groups and introduction of methoxy auxochromes. After twenty-four hours, the product (highly viscous pale brown oil) was isolated using aqueous work up. TLC analysis suggested a change in structure from (1A), $R_{\mathrm{f}}=0.74$, to a less polar product, $\mathrm{R}_{\mathrm{f}}=0.58$ and bands due to the presence of the methoxy groups were clearly visible in the infrared spectrum (Figure 5). Elemental analysis indicated that the agreement between the product and the target compound was good.

Figure 5. FTIR transmission spectrum (thin film) of compound (2) - vertical scale (\%) 
Both ${ }^{1} \mathrm{H}$ (Figure 6) and ${ }^{13} \mathrm{C}$ NMR spectral data (Figure 7) appeared to correspond well with the target structure, with shifts corresponding to the methoxy group (and confirming the absence of the hydroxyl group) clearly visible.

Figure 6. (a) ${ }^{1} \mathrm{H}$ NMR spectrum $\left(\mathrm{CDCl}_{3}\right)$ of compound (2)

Figure $7 .{ }^{13} \mathrm{C}$ NMR spectrum $\left(\mathrm{CDCl}_{3}\right)$ of compound (2) and proposed assignments

The ${ }^{13} \mathrm{C}$ NMR spectrum displayed the expected number of shifts, consistent with the proposed structure and the assignments were made on the basis of literature data for substituted benzene rings [19], again the shift at $56 \mathrm{ppm}$ is characteristic of the methoxy group (C1). The somewhat simpler

${ }^{31} \mathrm{P}$ NMR spectrum showed a main singlet at $10.13 \mathrm{ppm}$ with several smaller peaks and is in accordance with the values reported by Nair et al. [15] (a broad singlet at ca. $9.15 \mathrm{ppm}$ ) for similar cyclophosphazene species (herein based on the chemical modification of (1A)).

Having produced the target methoxyphenoxy compound (2), removal of the protecting methyl group (to yield the free hydroxyl group) was effected using boron tribromide (Scheme 4).

Scheme 4. Preparation of compound (3), showing the predominant isomer 
This commonly used reagent facilitates a relatively mild procedure (at $-62^{\circ} \mathrm{C}$ as the reaction is exothermic), rather than the somewhat harsher conditions required with more traditional boiling hydrohalic acids. The original intention was to allow the reaction to return slowly to room temperature over a period of two hours in line with literature reports and a preliminary experiment. However, approximately one hour into the reflux a large amount of rubbery amber solid precipitate formed in the reaction vessel; the reflux was halted and the solid removed from the flask for analysis. The solid was found to be soluble in methanol and acetone, but insoluble in dichloromethane (explaining the precipitation) and less polar solvents; infrared analysis showed the clear presence of the hydroxyl group. The crude product was recrystallised from a mixture of ethanol and water (70:30) and resulted in beige-coloured oil with an infrared spectrum similar to that of the crude material, albeit more sharply defined. For example, a band at $1265 \mathrm{~cm}^{-1}$, assigned to $\mathrm{P}-\mathrm{OPh}$ stretch and previously obscured by impurities, was now visible. High yields of (3) were obtained (never less than $85 \%$ and as high as $91.6 \%$ ) and the ${ }^{1} \mathrm{H}$ NMR spectrum (Figure 8) was consistent with the target molecule, albeit with traces of residual solvent present (principally as a broad singlet at $1.15 \mathrm{ppm}$ ).

\section{Figure 8. ${ }^{1} \mathrm{H}$ NMR spectrum $\left(\mathrm{CD}_{3} \mathrm{OD}\right)$ of compound (3}

Again, the aromatic region was quite complex, but bore similarities to that of the starting material. The methoxy singlet at $3.75 \mathrm{ppm}$ was absent, being replaced by a singlet at $4.90 \mathrm{ppm}$. The addition of a drop of deuterated water to the NMR tube resulted in a substantial reduction in the intensity of this

peak, showing it to be labile, as would be expected for a phenolic proton. The ${ }^{13} \mathrm{C}$ NMR spectrum is shown in Figure 9.

Figure 9. ${ }^{13} \mathrm{C}$ NMR spectrum $\left(\mathrm{CD}_{3} \mathrm{OD}\right)$ of compound (3) and proposed assignments 
In the final step, cyanation of (3) was carried out using a modification of a well-reported method 20]. During this step (Scheme 5), the reaction mixture turned a pale yellow colour on addition of the cyanogen bromide at $-15^{\circ} \mathrm{C}$ and eventually cloudy white as the introduction of triethylamine resulted in the production of triethylamine hydrobromide.

\section{Scheme 5. Preparation of compound (4), showing the predominant isomer}

At the conclusion of the reaction, the dry crude product resembled the material (3) and the principal means of determining whether the cyanation step had been effected successfully involved FT-IR spectroscopy. These spectral data initially suggested that the synthesis had not been successful, with little evidence of bands attributed to the cyanate group and with bands at $2497 \mathrm{~cm}^{-1}$ and $2604 \mathrm{~cm}^{-1}$, which could not be assigned in the target molecule. However, the broad $\mathrm{O}-\mathrm{H}$ band present at $3207 \mathrm{~cm}^{-1}$ in the spectrum of compound (3) (Figure 10) had been removed (the ${ }^{1} \mathrm{H}$ NMR spectrum also lacked the characteristic shift at ca. $4.8 \mathrm{ppm}$ ) and so this did suggest that the diphenol had undergone some modification. It is hypothesised that the bands at $2497 \mathrm{~cm}^{-1}$ and $2604 \mathrm{~cm}^{-1}$ (Figure 11, upper) arose from the presence of residual triethylammonium hydrobromide (particularly from the $\geq \mathrm{N}-\mathrm{H}^{+}$species).

Figure 10. FTIR transmission spectrum (thin film) of crude compound (3) (upper) and the same compound following recrystallisation (lower) - vertical scale (\%)

Figure 11. FTIR transmission spectrum (hexachlorobutadiene mull) of crude compound (4) (upper) and the same compound following washing (lower) - vertical scale (\%)

The corresponding ${ }^{1} \mathrm{H}$ NMR spectrum (Figure 12) contained a very broad shift at ca. 8 ppm and this was attributed to the labile proton in the same species.

Figure 12. Partial ${ }^{1} \mathrm{H}$ NMR spectrum $\left(\mathrm{CDCl}_{3}\right)$ of crude compound (4) showing labile proton 
Consequently, another rigorous washing step was employed and a second analysis, performed on the dried sample, thus treated, showed that the anomalous bands were no longer present. Furthermore, a fairly intense doublet ( 2166 and $2209 \mathrm{~cm}^{-1}$ ), characteristic of O-C $\equiv \mathrm{N}$ stretch in the cyanate, was now evident (Figure 11, lower). A small quantity of aliphatic material is evident in the FTIR spectrum $\left(2980,2925\right.$ and $\left.2736 \mathrm{~cm}^{-1}\right)$, presumably from residual $n$-hexane and perhaps arising from traces of ethyl bromide, the product of the von Braun side reaction [21], which is known to accompany preparations involving cyanogen bromide. Commercial cyanate monomers are prepared using cyanogen chloride, which effects a clean reaction, but the extreme toxicity of this reagent precludes its use in the laboratory.

\section{Figure 13. ${ }^{13} \mathrm{C}$ NMR spectrum $\left(\mathrm{CDCl}_{3}\right)$ of crude compound (4) and proposed assignments}

\subsection{Thermal polymerisation of the monomer and monomer blends}

In the first instance, an "uncatalysed" sample of (4) was analyzed individually using DSC at a variety of heating rates (a typical dynamic scan, $10 \mathrm{~K}$ min ${ }^{-1}$, is shown in Figure 14). A melting endotherm is evident (peak minimum $45^{\circ} \mathrm{C}$ ) suggesting a reasonably high degree of purity (Table 1). This precedes a shallow exothermic peak spanning ca. $110-200^{\circ} \mathrm{C}$ (with a main peak maximum at $145^{\circ} \mathrm{C}$ ).

Table 1. Dynamic DSC data for dicyanate monomer (4) as a function of heating rate. 
The relatively low cure onset temperature is in broad agreement with the figure reported for a similar compound by Nair et al. [15]. The shape of the peak is quite even and appears almost Gaussian and a polymerization enthalpy of $\Delta \mathrm{H}=-96 \mathrm{~J} \mathrm{~g}^{-1}$ of monomer or $-37 \mathrm{~kJ}^{-1}$ of cyanate groups was recorded. This figure is quite low for a cyanate monomer (a polymerisation enthalpy of $\Delta \mathrm{H} \mathrm{ca} .-105 \mathrm{~kJ} \mathrm{~mol}^{-1}$ per OCN group might be more typical [22]), suggesting that the monomer had not achieved full conversion during the timescale of the $\mathrm{DSC}$ experiment. Beyond $300{ }^{\circ} \mathrm{C}$, the baseline begins to climb again suggesting the onset of thermal degradation. A sample of the dicyanate, previously held for 30 minutes at $250{ }^{\circ} \mathrm{C}$, was rescanned using MDSC using a linear heating rate of $10 \mathrm{~K}$ $\mathrm{min}^{-1}$. The thermogram (Figure 14) shows a clear inflexion at $50-60^{\circ} \mathrm{C}$ in the reversible heat flow data, appearing to confirm a very low $\mathrm{T}_{\mathrm{g}}$ (presumably of uncured material) under these conditions, although there is evidence for a small $155-165^{\circ} \mathrm{C}$, which is more in line with observations made by Nair et al. (i.e. $160-175^{\circ} \mathrm{C}$ ). The partially-cured cyanate appeared to undergo further cure at $225^{\circ} \mathrm{C}$ during the heating programme, lending credence to the low degree of cure. Furthermore, a TMA experiment, performed on the same sample, yielded a marked transition of $60{ }^{\circ} \mathrm{C}$ (obtained from extrapolation of tangents from the two slopes) and a weaker transition at the higher temperature, supporting the observation of a low $\mathrm{T}_{\mathrm{g}}$, although the cure had not been optimised to yield the highest degree of cure.

Figure 14. DSC thermogram of compound (4) at $10 \mathrm{~K} \mathrm{~min}^{-1}$ under flowing nitrogen (upper) the rescan is shown below. Exothermic heat flow is show upwards 


\subsection{Kinetic analysis of the thermal polymerisation of the monomer}

DSC data had already been obtained for the cure at a variety of different heating rates and these data were analysed using an Excel spreadsheet designed to perform automatic baseline correction. Phenomenological kinetic analysis was performed using a method reported by Barton [23], involving a modified Arrhenius equation:

$$
\ln (r)-n \cdot \ln (1-\alpha)=\ln (A)-E_{\mathrm{a}} / R T
$$

where $r=$ apparent rate of reaction, $n=$ order of reaction, $\alpha=$ degree of conversion, $A=$ pre-exponential factor, $E_{\mathrm{a}}=$ activation energy $\left(\mathrm{kJ}\right.$ mol $\left.{ }^{-1}\right), R=$ gas constant $\left(8.314 \mathrm{~J} \mathrm{~K}^{-1} \mathrm{~mol}^{-1}\right), T=$ absolute temperature $(\mathrm{K})$.

Thus, a plot of $\ln (r)-n \cdot \ln (1-\alpha)$ versus reciprocal temperature for data obtained at constant heating rate for several different possible values of $n(n=1,2,3)$ over the range of conversion $(0.05 \leq \alpha \leq 0.95)$, yields the gradient $E_{\mathrm{a}} / R$ and intercept $\ln A$ (Figure 15).

Figure 15. Arrhenius plot for the cure of compound (4) at $10 \mathrm{~K} \mathrm{~min}^{-1}$ under flowing nitrogen with data fitted to $n=1$ (top), $n=2$ (middle), and $n=3$

\section{(bottom)}


Least squares regression analysis revealed correlation coefficients $\left(r^{2}\right)$ of $0.957,0.996$ and 0.970 for $n=1,2$, and 3 respectively (indicating the polymerisation is best fitted with a second order model, which is in accord with many literature reports for similar polycyclotrimerisation reactions [22]). The Arrhenius parameters obtained from the data are shown in Table 2 (the $10 \mathrm{~K} \mathrm{~min}^{-1}$ heating rate data appear anomalous). The actual numbers obtained should be treated with a little caution as the actual cyanate monomer is likely to comprise a mixture of monomers with differing substitution patterns (with mono-, di- and trisubstituted rings based on cyanate content), but the order of magnitude for the activation energy is in line with other reported values [22]. Unfortunately, Nair et al. did not obtain quantitative thermal data for the polymerisation of their materials so a direct comparison was not possible.

\section{Table 2. Arrhenius kinetic parameters for the thermal cure of compound (4) fitted for $n=2$}

\subsection{Thermal polymerisation of the monomer blends}

It was decided to prepare a series of selected binary blends/copolymers and 2,2-bis(4-cyanatophenyl)propane was chosen for this purpose. Thus, a series of catalysed blends containing compound (4) (10, 20, and 30 weight \%) was prepared (Table 3) and analysed using DSC (Figure 16). The endotherm at ca. 80 ${ }^{\circ} \mathrm{C}$ corresponds to the melting temperature of the commercial dicyanate monomer, the sharpness of the transition indicating its purity.

Table 3. Sample blends prepared and analysed in this work 
Under these analysis conditions, 'uncatalysed' AroCy B-10 (i.e. without the addition of a specific catalyst) displays an exothermic peak maximum at ca. $297{ }^{\circ} \mathrm{C}$ and the binary blends all appear to commence polymerization as soon as the blend undergoes fusion. Owing to the coincidence of the two processes, the exotherms appeared truncated and thus the polymerization enthalpies were not determined (the measurement would have yielded a reduced enthalpy). However, an estimate of the enthalpy from the apparent onset yielded a value of $\Delta \mathrm{H}$ of the same order of magnitude as other measurements made on AroCy B-

10. The lack of significant exotherm on the rescan experiments also appeared to confirm that the polymerization reactions proceeded to completion under these conditions.

\section{Table 4. Dynamic DSC data for binary blends containing dicyanate monomer (4) as a function of heating rate.}

It is apparent that as the composition of the sample contains more of the novel cyanate monomer (4), the thermogram appears to display a more sloping baseline, perhaps reflecting the change in the heat capacity of the ensuing blend. Each sample was subjected to a re-scan experiment in order to determine the $\mathrm{T}_{\mathrm{g}}$ of the cured polycyanurate. Under the analysis conditions employed the samples did apparently undergo cure (as evidenced by the absence of the residual exotherm), although the conditions were not optimised to effect full cure. The discontinuity in the baseline was quite difficult to discern in sample (4-B10-90) (containing $10 \%(4))$ and (4-B10-80) (containing $20 \%(4)$ ), although a stronger feature was evident in the thermogram of the material containing $30 \%$ of the new material (4-B10-70). However, the magnitude of the $\mathrm{T}_{\mathrm{g}}$ was quite disappointing e.g. sample (4-B10-90) appears to show a shallow $\mathrm{T}_{\mathrm{g}}$ at $c a .163{ }^{\circ} \mathrm{C}$, and no further features up to $300^{\circ} \mathrm{C}$, at which point the sample was quenched. 


\section{Figure 16. DSC thermograms of blend containing AroCy B-10 and $10 \mathrm{wt} \%$ (4) at $10 \mathrm{~K} \mathrm{~min}^{-1}$ in air and rescan (lower)}

The cooling step does indicate a change in gradient at $c a .170-180{ }^{\circ} \mathrm{C}$, which does correspond reasonably well with the $\mathrm{T}_{\mathrm{g}}$ on rescan. When the composition of the sample contains more of the new additive, e.g. sample (4-B10-80), the $\mathrm{T}_{\mathrm{g}}$ is raised to $c a .190{ }^{\circ} \mathrm{C}$ on rescan, but disappointingly evidence of an exothermic transition was observed at $c a .280^{\circ} \mathrm{C}$, possibly due to the decomposition of the AroCy B10 component. Finally, sample (4-B10-70) displayed a value of $\mathrm{T}_{\mathrm{g}}$ at ca. $180^{\circ} \mathrm{C}$ on rescan, and also evidence of an exothermic transition at ca. $275^{\circ} \mathrm{C}$. Although the measured values were difficult to discern, they were unexpectedly low, as the presence of the substituted tricyclophosphazene was hoped to decrease the freedom of rotation and thus raise $\mathrm{T}_{\mathrm{g}}$. In order to examine the thermo-oxidative stability of the blends in greater details, a series of TG analyses were performed on cured samples and the results are discussed below.

\subsection{Thermo-oxidative and thermal degradation of the polycyanurates}

A sample of the (partially) cured polycyanurate (4), as a homopolymer, was tested by TG analysis in both air and nitrogen atmospheres and the data are presented in Table 5. In air, the thermo-oxidative degradation appeared to commence (with a significant mass loss of 5\%) at approximately $381{ }^{\circ} \mathrm{C}$, although there was evidence of perhaps minor loss of residual solvent $(<1 \%)$ before this point. The data support the hypothesis that the monomer had not undergone complete cure using the schedule employed. In nitrogen, the corresponding thermal degradation appeared to commence at around $366^{\circ} \mathrm{C}$ (surprisingly lower than in air and indicating the operation of a different degradation mechanism). These data compare favourably with the materials reported by Nair et al. [15], 
for which mass losses of $5 \%$ were found to occur at $430^{\circ} \mathrm{C}$ in nitrogen. Similarly, char residues of $50 \%$ (at $710^{\circ} \mathrm{C}$ in air and $816^{\circ} \mathrm{C}$ in nitrogen) in the present study are of the same order of magnitude with those reported. A period of relatively little mass loss was recorded before the remainder of the polycyanurate began to degrade above $680-800^{\circ} \mathrm{C}$, depending on the atmosphere. Neither homopolymer lost all its mass, but the char yields at $1000^{\circ} \mathrm{C}$ were less than $3 \%$ in both atmospheres, presumably containing inorganic residues.

\section{Table 5. TG data for the thermal/thermo-oxidative degradation of the cured homopolymer and copolymers}

One of the initial aims of this study was to introduce the tricyclophosphazene into a commercial cyanate (AroCy B10) and to examine the effect on the thermal/thermo-oxidative stability, in the hope that the latter might be improved. Consequently, compound (4) was combined with AroCy B10 at three selected levels of incorporation (10, 20 and $30 \mathrm{wt} \%$ of the tricyclophosphazene). The monomers were pre-mixed before being catalysed with copper(II) acetylacetonate (300 ppm $\left.\mathrm{Cu}^{2+}\right)$ and nonylphenol (4 phr) and subjected to a thermal cure (1 hour @ 180 ${ }^{\circ} \mathrm{C}, 2$ hours @ 200 ${ }^{\circ} \mathrm{C}$ and 1 hour@ $250^{\circ} \mathrm{C}$ under nitrogen). TG analysis was performed (in air) in a similar fashion to the analyses of the homopolymers: cured, powdered samples were heated to $50^{\circ} \mathrm{C}$, held at this temperature for one minute to equilibrate before being heated to $1000^{\circ} \mathrm{C}$ at a heating rate of $10 \mathrm{~K} \mathrm{~min}^{-1}$. Once the sample had reached the final temperature it was held isothermally for 4 hours. However, unfortunately the data for the copolymers (containing between 10 and $30 \mathrm{wt} \%$ of the tricyclophosphazene) were disappointing as the thermal stability showed a progressive reduction in the onset of degradation with increasing phosphazine content. This finding seems counterintuitive, as the 
DSC data for the blends suggested that they had attained full cure. However, it may be that the monomers had co-cured to form and interpenetrating network rather than a copolymer and it is true that the schedule/catalyst package was not optimised to effect copolymerisation.

\section{Experimental}

\subsection{Materials}

The following reagents were obtained from a range of sources (indicated in parentheses, along with the purity where noted) and were all used as received, unless otherwise noted in the experimental text. Dichloromethane, chloroform, sodium carbonate, anhydrous potassium carbonate, calcium chloride, and glacial acetic acid (all of GPR grade and obtained from Fisher Scientific). $\quad N, N$-Dimethylacetamide $(99 \%), 2,2,4,4,6,6-h e x a c h l o r o-2 \lambda^{5}, 4 \lambda^{5}, 6 \lambda^{5}-$ [1,3,5,2,4,6]-triazatriphosphinine (99\%), phenol (99+\%), triethylamine (99\%), $\mathrm{CDCl}_{3}, n$-heptane (99+ \%), and boron tribromide (1.0 $\mathrm{M}$ in dichloromethane) (Aldrich Chemical Co.). Cyanogen bromide (97\%) and 4-methoxyphenol (99\%) (Acros Organics). Anhydrous magnesium sulphate, sodium hydroxide, and acetone (all GPR grade and obtained from BDH). Tri $n$-butylhexadecylphosphonium bromide (98+\%) (Lancaster). The binary blends, combining 2,2-bis(4cyanatophenyl)propane (Ciba Geigy as AroCy B-10, 99+\%) and the novel cyclotriphosphazene (Table 4) were catalysed using copper(II) acetylacetonate (99+\%) (Sigma-Aldrich).

\subsection{Apparatus}


Fourier transform infrared (FT-IR) spectra were recorded using a Perkin-Elmer (system 2000 FT-IR) spectrometer interfaced with a PC running PE-Spectrum v 2.00 software or a Nicolet Avatar 320 FT-IR spectrometer running Nicolet OMNIC ESP 5.1 software. The samples were presented on an ATR module, 16 scans, at a resolution of $4 \mathrm{~cm}^{-1}$, were recorded and co-added to produce the final spectrum.

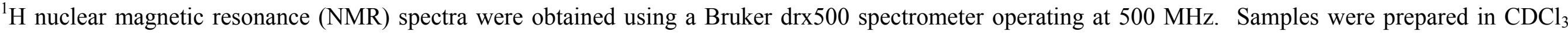
unless stated to the contrary and spectra were acquired at $25^{\circ} \mathrm{C}$ using tetramethylsilane (TMS) as an internal standard. ${ }^{13} \mathrm{C}$ and ${ }^{31} \mathrm{P}$ NMR spectra were obtained using the same spectrometer operating at 75.47 and $121.50 \mathrm{MHz}$ respectively.

Differential scanning calorimetry (DSC) was carried out in air using a TA Instruments MDSC 2920 on samples (ca. $3.5 \pm 0.5 \mathrm{mg})$ over the range $40-350^{\circ} \mathrm{C}$ at a heating rate of $10 \mathrm{~K} \mathrm{~min}^{-1}$ ) using sealed, crimped aluminium pans. Following the initial $10 \mathrm{~K} \mathrm{~min}^{-1}$ scan, samples were quenched and cooled at the same rate prior to a second, re-scan, experiment at $10 \mathrm{~K} \mathrm{~min}^{-1}$. The re-scan was performed in order to discern the glass transition temperature $\left(\mathrm{T}_{\mathrm{g}}\right)$ and this feature was determined by measuring the mid-point position of the discontinuity of the baseline.

Thermogravimetric (TG) analysis was performed using a TA Instruments 2950 thermal analyser on powdered cured samples (ca. $18 \pm 2 \mathrm{mg}$ ) in both air and nitrogen $20 \mathrm{~cm}^{3} \mathrm{~min}^{-1}$ ) using a platinum boat. Prior to analysis, the catalysed blends were submitted to the following cure schedule (in nitrogen): $180^{\circ} \mathrm{C}$ ( 1 hour), $200^{\circ} \mathrm{C}$ ( 2 hours $), 250^{\circ} \mathrm{C}$ ( 1 hour) before being cooled and ground with a pestle and mortar. For the analysis in the oxidising atmosphere, cured, powdered samples were heated to $50^{\circ} \mathrm{C}$, held at this temperature for one minute to equilibrate before being heated to $1000^{\circ} \mathrm{C}$ at a heating rate of $10 \mathrm{~K}$ min ${ }^{-1}$. Once the sample had reached the final temperature it was held isothermally for 4 hours. For the analysis in flowing nitrogen, the cured, powdered sample was heated to 
$50^{\circ} \mathrm{C}$, held at this temperature for one minute to equilibrate before being heated to $1000^{\circ} \mathrm{C}$ at a heating rate of $10 \mathrm{~K}$ min ${ }^{-1}$. Once the sample had reached the final temperature it was held isothermally for 18 hours.

Elemental analysis was performed using a Leeman Labs., Inc. CE 440 elemental analyser. Melting temperatures were determined using a Kopfler flat bed micro melting point apparatus and a heating rate of $4 \mathrm{~K} \mathrm{~min}^{-1}$.

Unless otherwise stated, all glassware was dried in an oven at $110^{\circ} \mathrm{C}$ and allowed to cool in a desiccator prior to use. For those reactions carried out under an inert atmosphere, this was obtained by passing nitrogen through sulphuric acid, calcium chloride and self-indicating silica gel to remove residual moisture.

\subsection{Synthesis and characterization}

\subsubsection{Preparation of partially-protected cyclotriphosphazene (1)}

To a three-necked round bottom flask were added 2,2,4,4,6,6-hexachloro- $2 \lambda^{5}, 4 \lambda^{5}, 6 \lambda^{5}-[1,3,5,2,4,6]$-triazatriphosphinine (or hexachlorocyclotriphosphazene) (10.0 g, $28.6 \mathrm{mmol}$.) and tributylhexadecylphosphonium bromide $\left(1.46 \mathrm{~g}, 2.86 \mathrm{mmol}\right.$.) dissolved in dichloromethane $\left(86 \mathrm{~cm}^{3}\right)$. The contents of the flask were stirred vigorously while an aqueous solution of phenol $\left(10.77 \mathrm{~g}, 114.4 \mathrm{mmol} ., 39 \mathrm{~cm}^{3}\right)$ and sodium hydroxide $\left(9.20 \mathrm{~g}, 230 \mathrm{mmol}\right.$.) $\left(29 \mathrm{~cm}{ }^{3}\right)$ was added dropwise. The resulting mixture was stirred for forty minutes and the organic layer separated, washed with water $\left(2 \times 50 \mathrm{~cm}^{3}\right)$ and dried over magnesium sulphate. The solvents were evaporated to leave highly viscous colourless oil (yield $16.52 \mathrm{~g}$ ). Three spots were visible under UV lamp (254 nm) on a TLC plate (dicloromethane: $n$-heptane 1:1). 
Elemental analysis calculated for $\mathrm{C}_{24} \mathrm{H}_{20} \mathrm{~N}_{3} \mathrm{O}_{4} \mathrm{P}_{3} \mathrm{Cl}_{2}: 49.83 \% \mathrm{C}, 3.46 \% \mathrm{H}, 7.27 \% \mathrm{~N}$; found: $49.31 \% \mathrm{C}, 3.30 \% \mathrm{H}, 7.08 \% \mathrm{~N}$ (from an initial, small-scale preparation); $49.57 \% \mathrm{C}, 3.26 \% \mathrm{H}, 7.23 \% \mathrm{~N}$ (75\% yield on larger scale, $10 \mathrm{~g}$, preparation).

The crude oil was dissolved in the minimum quantity of $n$-heptane:dichloromethane $(3: 2)\left(100 \mathrm{~cm}^{3}\right)$ and added to a slurry-packed column of silica. The product was eluted with a similar eluent using flash chromatography and the fractions $\left(c a .100 \mathrm{~cm}^{3}\right)$ characterised using TLC ( $n$-heptane:dichloromethane, 3:2) and fractions showing the same $\mathrm{R}_{\mathrm{f}}$ values were combined. The first (smaller) component eluted in a single fraction $\left(\mathrm{R}_{\mathrm{f}}=0.74\right)$ and the two fractions (\#5 and \#6 in a series of 10) also showed a single spot and these were believed to contain some residual phase transfer catalyst co-eluting with the sample; there were not combined with the rest. The remaining fractions were combined and the solvent removed on a rotary evaporator to yield a viscous pale yellow oil (6.38 g), designated (1A). The final component was present in eleven fractions $\left(\mathrm{R}_{\mathrm{f}}=0.67\right)$ and following concentration a colourless viscous oil was obtained $(0.93 \mathrm{~g})$, designated (1B). A repeat experiment yielded two identical fractions (4.38 $\mathrm{g}$ and $0.41 \mathrm{~g}$ respectively, with identical $\mathrm{R}_{\mathrm{f}}$ values) and each was combined with its duplicate with the same designation. The fractions were analysed by ${ }^{1} \mathrm{H}$ NMR and ${ }^{31} \mathrm{P}$ and infrared spectroscopy.

Fraction (1A): FTIR $\left(\mathrm{cm}^{-1}\right)$ : $1263\left(\mathrm{P}-\mathrm{OPh}\right.$ stretch), 1235 (P-Cl stretch), 766 and $688\left(\mathrm{Ar}-\mathrm{H}\right.$ out of plane bends); ${ }^{31} \mathrm{P}$ NMR $(\mathrm{ppm}) 20-21\left[\mathrm{~N}=\underline{\mathrm{P}}(\mathrm{Cl})_{2}\right], 18.6-19.0$ $[\mathrm{N}=\underline{\mathrm{P}}(\mathrm{Cl})(\mathrm{OPh})]$ and 4.47-5.97 $\left[\mathrm{N}=\underline{\mathrm{P}}(\mathrm{OPh})_{2}\right] ;{ }^{1} \mathrm{H}$ NMR (ppm, TMS) 6.9-7.3 (complex region showing several mono-substituted aromatic rings). 
Fraction (1B): ${ }^{31} \mathrm{P}$ NMR (ppm) 20 (triplet) $\left[\mathrm{N}=\underline{\mathrm{P}}(\mathrm{Cl})_{2}\right]$ and 5-7 (doublet) $\left[\mathrm{N}=\underline{\mathrm{P}}(\mathrm{OPh})_{2}\right] ;{ }^{1} \mathrm{H}$ NMR (ppm, TMS) 6.9-7.3 (complex region showing several monosubstituted aromatic rings).

\subsubsection{Preparation of methoxyphenoxy-substituted cyclotriphosphazene (2)}

The major component resulting from the first preparative step (1A) (5.71 g), 4-methoxyphenol (5.03 g, 40.6 mmol) and potassium carbonate (9.10 g, 68.5 mmol) were dissolved in $N, N$-dimethylacetamide, DMAc, $\left(45 \mathrm{~cm}^{3}\right)$ and placed in a three-necked flask fitted with a reflux condenser and nitrogen inlet. The solution was placed under a nitrogen blanket, heated to reflux $\left(140^{\circ} \mathrm{C}\right)$ and left to stir for twenty-four hours with occasional monitoring with TLC. At the conclusion of the preparation, the sample mixture was allowed to cool to room temperature. A second preparation was undertaken on a similar scale: compound (1) (5.65 g) and, as the TLC yielded near identical $R_{f}$ values, the samples were combined. Dichloromethane $\left(25 \mathrm{~cm}^{3}\right)$ was added to the combined samples and the resulting mixture washed with a $1.0 \mathrm{M}$ aqueous solution of sodium hydroxide $\left(2 \times 25 \mathrm{~cm}^{3}\right)$ and brine $\left(2 \times 25 \mathrm{~cm}^{3}\right)$ to remove the inorganic byproduct. The visibly paler organic layer was then dried over magnesium sulphate and the solvent removed by rotary evaporation to yield viscous amber oil (yield 8.61 g). The oil was dried overnight in a vacuum oven at $40^{\circ} \mathrm{C}$ to remove any remaining solvent, particularly DMAc (purified yield $8.06 \mathrm{~g}$ ), and the product, which had become markedly more viscous, was analysed by ${ }^{1} \mathrm{H}$ and ${ }^{13} \mathrm{C}$ NMR and infrared spectroscopy and elemental analysis.

Compound (2). A single spot $\left(\mathrm{R}_{\mathrm{f}}=0.58\right)$ was visible under UV lamp $(254 \mathrm{~nm})$ on a TLC plate $(n$-heptane:dicloromethane, $70: 30)$. FTIR $\left(\mathrm{cm}^{-1}\right): 3068(\mathrm{Ph}-\mathrm{H}$ stretch), 2933 (methyl C-H stretch), 2835 ( $\mathrm{CH}_{3}-\mathrm{O}-$ stretch), 1296 (P-[OPhOCH$\left.{ }_{3}\right]$ stretch), 1265 (P-OPh stretch), 1101 (C-O-C stretch); Elemental analysis, 
calculated for $\mathrm{C}_{39} \mathrm{H}_{36} \mathrm{~N}_{3} \mathrm{O}_{9} \mathrm{P}_{3}: 59.8 \% \mathrm{C}, 4.6 \% \mathrm{H}, 5.4 \% \mathrm{~N}$; found: $59.8 \% \mathrm{C}, 4.65 \% \mathrm{H}, 5.78 \% \mathrm{~N} .500 \mathrm{MHz}{ }^{1} \mathrm{H} \mathrm{NMR} \delta_{\mathrm{H}}\left(\mathrm{CDCl}{ }_{3}\right.$, ppm from TMS) 7.3-6.6 (14H, mono-substituted Ar- $\underline{\mathrm{H}}), 3.75$ (s, $\left.\underline{\mathrm{C}}_{3} \mathrm{O}\right) .{ }^{13} \mathrm{C}$ NMR $\delta_{\mathrm{C}}\left(\mathrm{CDCl}_{3}\right.$, ppm from TMS) 157 (C(2), $\left.\mathrm{CH}_{3}-\mathrm{O}-\underline{\mathrm{C}}\right), 150$ (C(6), PO-C $), 144(\mathrm{C}(8), \mathrm{Ar}$ meta to -OP), $129\left(\mathrm{C}(4)\right.$, Ar meta to $\left.-\mathrm{OCH}_{3}\right), 124(\mathrm{C}(9)$, Ar para to $-\mathrm{OP}), 121\left(\mathrm{C}(5)\right.$, Ar ortho to $\left.-\mathrm{OCH}_{3}\right), 120(\mathrm{C}(7)$, Ar ortho to $\mathrm{OP}), 114(\mathrm{C}(3), \mathrm{Ar}$ ortho to $-\mathrm{OCH}), 56$ $\left(\mathrm{C}(1), \underline{\mathrm{CH}}_{3} \mathrm{O}\right)$.

\subsubsection{Preparation of hydroxyphenoxy-substituted cyclotriphosphazene (3)}

A 3-neck round bottomed flask, equipped with a magnetic stirrer bar, reflux condenser, nitrogen inlet, septum and nitrogen outlet was charged with the methoxyphenoxy-substituted cyclotriphosphazene (2) $(4.03 \mathrm{~g})$ and dichloromethane $\left(50 \mathrm{~cm}^{3}\right)$. The vessel was purged with nitrogen and cooled to $-62{ }^{\circ} \mathrm{C}$ by immersion in slurry of dry ice and acetone and a $1.0 \mathrm{M}$ solution of boron tribromide in dichloromethane $\left(15 \mathrm{~cm}^{3}\right)$ was slowly injected via a glass syringe. The reaction mixture was allowed to return to room temperature over the course of three hours; the nitrogen supply was switched off and the mixture was then heated to reflux and maintained at this temperature overnight, during which time an amber, waxy precipitate had appeared in the flask. After cooling the vessel to room temperature, the precipitate was removed and allowed to dry to yield a waxy brown solid $(6.31 \mathrm{~g})$. The preparation was repeated on a similar scale and the products, having similar analyses by ${ }^{1} \mathrm{H},{ }^{13} \mathrm{C}$ and infrared spectroscopy, were combined. 
FTIR $\left(\mathrm{cm}^{-1}\right) 3329\left(\mathrm{bs}, v_{\mathrm{O}-\mathrm{H}}\right) 1592\left(\mathrm{~m}, v_{\mathrm{Ar} \mathrm{C}-\mathrm{C}}\right) 1508\left(\mathrm{~s}, v_{\mathrm{Ar} \mathrm{C}-\mathrm{C}}\right) 1489\left(\mathrm{~s}, v_{\mathrm{Ar} \mathrm{C}-\mathrm{C}}\right) 1265(\mathrm{P}-\mathrm{OPh}$ stretch $) 1175\left(\mathrm{bs}, v_{\mathrm{C}-\mathrm{OH}}\right) 836\left(\mathrm{~s}, \delta_{\mathrm{Ar}-\mathrm{H}}\right) 770\left(\mathrm{~s}, \delta_{\mathrm{Ar}-\mathrm{H}}\right) 689\left(\mathrm{~s}, \delta_{\mathrm{Ar}-\mathrm{H}}\right)$. ${ }^{1} \mathrm{H}$ NMR $\delta_{\mathrm{H}}\left(500 \mathrm{MHz}, \mathrm{CD}_{3} \mathrm{OD}\right.$, ppm from TMS) 7.2-6.6 (c.m., Ar- $\left.\underline{\mathrm{H}}\right), 4.9(1 \mathrm{H}, \mathrm{s}, \mathrm{OH}) .{ }^{13} \mathrm{C} \mathrm{NMR} \delta_{\mathrm{C}}\left(\mathrm{CD}_{3} \mathrm{OD}, \mathrm{ppm}\right.$ from TMS) $156(\mathrm{C}(1), \mathrm{HO}-\underline{\mathrm{C}}), 152(\mathrm{C}(5)$, PO- $\underline{C}), 144(\mathrm{C}(7)$, Ar meta to $-\mathrm{OP}), 130(\mathrm{C}(3)$, Ar meta to $-\mathrm{OH}), 126(\mathrm{C}(8)$, Ar para to $-\mathrm{OP}), 123(\mathrm{C}(2)$, Ar ortho to $-\mathrm{OH}), 122(\mathrm{C}(6), \mathrm{Ar}$ ortho to $\mathrm{OP}), 116$ (C(2), Ar ortho to $-\mathrm{OH})$.

\subsubsection{Preparation of cyanatophenoxy-substituted cyclotriphosphazene (4)}

A 3-neck round bottom flask, equipped with a magnetic stirrer bar, two septa and a condenser attached to a drying tube (containing calcium chloride) was charged with 1,1',3-tris(4-hydroxyphenoxy)-3',5,5-tetraphenoxycyclotriphosphazene (4) (3.15 g, 4.25 mmol.) and cyanogen bromide (1.38 g, 13 mmol.). The reactants were dissolved in acetone $\left(70 \mathrm{~cm}^{3}\right)$ and the solution cooled below $-10{ }^{\circ} \mathrm{C}$ using a methanol/card-ice bath. Triethylamine $(1.32 \mathrm{~g}, 13 \mathrm{mmol}$.) was added dropwise via a dropping funnel over a period of fifteen minutes. The mixture was stirred for thirty minutes at a rate such that the reaction mixture was maintained below $-10{ }^{\circ} \mathrm{C}$. The reaction mixture was then allowed to warm to room temperature and filtered to remove a cream coloured precipitate and the remaining amber liquid was quenched by adding it to an ice/water bath $\left(100 \mathrm{~cm}^{3}\right)$. The product was extracted with dichloromethane $\left(3 \mathrm{x} 100 \mathrm{~cm}^{3}\right)$ and the organic extracts were combined prior to washing with a $1.0 \mathrm{M}$ aqueous solution of sodium hydroxide $\left(2 \times 100 \mathrm{~cm}^{3}\right)$ and saturated brine $\left(2 \times 100 \mathrm{~cm}^{3}\right)$. The organic phase was dried over magnesium sulphate to yield a clear yellow solution. The solvent was removed on a rotary evaporator leaving an amber crystalline solid, which was analysed using ${ }^{1} \mathrm{H}$ and ${ }^{13} \mathrm{C}$ NMR spectroscopy. The solid was ground in cold $n$-hexane and then dissolved in dichloromethane 
before being washed with water $\left(5 \times 50 \mathrm{~cm}^{3}\right)$ and concentrated on a rotary evaporator to yield a pale yellow powder; the latter was analysed by ${ }^{1} \mathrm{H}$ and ${ }^{13} \mathrm{C}$ NMR spectroscopy. DSC analysis revealed a m.p. of $c a .45^{\circ} \mathrm{C}$ at a heating rate of $10 \mathrm{~K} \mathrm{~min}^{-1}$.

FTIR (mull, hexachlorobutadiene, $\left.\mathrm{cm}^{-1}\right) 3068\left(\mathrm{w}, v_{\mathrm{Ar}-\mathrm{H}}\right) 2202$ and $2168\left(\mathrm{~m}, \mathrm{v}_{\mathrm{O}-\mathrm{CN}}\right) 1610\left(\mathrm{~m}, v_{\mathrm{Ar} \mathrm{C}-\mathrm{C}}\right) 1563\left(\mathrm{~s}, v_{\mathrm{Ar} \mathrm{C}-\mathrm{C}}\right) 1489\left(\mathrm{~m}, v_{\mathrm{Ar} \mathrm{C}-\mathrm{C}}\right) 1268(\mathrm{~m}) 1169\left(\mathrm{bs}, v_{\mathrm{C}-\mathrm{OH}}\right)$ $854\left(\mathrm{~s}, \delta_{\mathrm{Ar}-\mathrm{H}}\right) 794\left(\mathrm{~s}, \delta_{\mathrm{Ar}-\mathrm{H}}\right) 688\left(\mathrm{~s}, \delta_{\mathrm{Ar}-\mathrm{H}}\right) .300 \mathrm{MHz}{ }^{1} \mathrm{H}$ NMR $\delta_{\mathrm{H}}\left(\mathrm{CDCl}_{3}, \mathrm{ppm}\right.$ from TMS $) 792-7.90\left(4 \mathrm{H}, \mathrm{d}, J_{\mathrm{H}}=8.9 \mathrm{~Hz}, \mathrm{Ar}-\mathrm{H}_{\mathrm{a}}\right), 7.36-6.33\left(4 \mathrm{H}, \mathrm{d}, J_{\mathrm{H}}=8.8 \mathrm{~Hz}\right.$, Ar- $\left.H_{b}\right), 7.14-7.12\left(4 \mathrm{H}, \mathrm{d}, J_{\mathrm{H}}=9.9 \mathrm{~Hz}, \mathrm{Ar}-\mathrm{H}_{\mathrm{c}}\right), 7.05-7.02\left(4 \mathrm{H}, \mathrm{d}, J_{\mathrm{H}}=9.8 \mathrm{~Hz}, \mathrm{Ar}-\mathrm{H}_{\mathrm{d}}\right)$.

\section{Conclusions}

Although the cyanate monomer (which is believed to be a mixture of isomers) was synthesised successfully with an overall yield of ca. $35 \%$ for a multi-step procedure, it was hoped that a higher yield might be attained. The route employed by Nair et al. in their publication [15] (which dealt with a similar compound) was somewhat higher and executed more rapidly, albeit using more hazardous conditions in sodium sand. Nevertheless, this might be worthy of further examination in subsequent attempts to produce this compound in greater quantity prior to combustion tests. Future work with these materials will concentrate on examining the nature of the catalyst package to promote a greater degree of conversion and copolymerisation.

\section{Acknowledgements}


We thank the MoD for funding a portion of this work in the form of a studentship (MAP) and we are grateful to Drs Adam Chaplin (formerly of DERA) and Richard Allington (Dstl) for useful discussions during the course of the early work. At the University of Surrey we thank Ms. Judith Peters for performing the elemental analyses, Mr James P Bloxsidge for obtaining the NMR spectra, Dr Duncan Gillies for invaluable assistance with ${ }^{31} \mathrm{P}$ NMR spectral interpretation and Dr Amy Mitchell (GnoSys UK Ltd.) for undertaking some of the thermal analyses.

\section{References}

1. Shimp DA, Chin B. Electrical properties of cyanate ester resins and their significance for applications, Chapter 3 in Chemistry and Technology of Cyanate Ester Resins, I. Hamerton (Ed.) Blackie Academic and Professional: Glasgow, 1994

2. Alger MSM. 'High-temperature and fire resistant polymers' Chapter 3 in Specialty Polymers, R. W. Dyson (Ed.) Blackie Academic and Professional: London, 1998

3. Shaw SJ. Additives and modifiers for epoxy resins, in Chemistry and Technology of Epoxy Resins, B. Ellis (Ed.) Blackie: Glasgow, 1993, pp. 117-143

4. Nelson GL. Fire and polymers: an overview, in Fire and Polymers. II. Materials and Tests for Hazard Prevention, Nelson G.L. (Ed.) ACS Symp. Ser. 599, ACS: Washington DC, 1994, pp. 1-26.

5. Shimp DA, Christenson JR, Ising SJ. 34 ${ }^{\text {th }}$ Int. SAMPE Symp. Exhib. 1989; 34: 222

6. Stevens GC and Mann AH. Risks and benefits in the use of flame retardants in consumer products, DTI Report: London, 1999 
7. van Glesch GJ. Environmental health criteria 218 - flame retardants: tris-(2-butoxyethyl)phosphate, tris-(2-ethylhexyl)phosphate and tetrakis(hydroxymethyl)phosphonium salts. WHO: Geneva, 2000

8. U.S. Environmental Protection Agency, EPA/600, vols. 1-3. US GPO: Washington DC, 1994

9. Lu S-Y, Hamerton I. Prog. Polym. Sci. 2002; 27: 1661-1712

10. Ramirez ML, Walters R, Savitski REP, Lyon RE. Thermal decomposition of cyanate ester resins, Final Report DOT/FAA/AR-01/32 for the U.S. Department of Transportation, Washington D.C., September 2001

11. Lyon RE, Walters R, Ganghi S. Combustibility of cyanate ester resins, Final Report DOT/FAA/AR-02/44 for the U.S. Department of Transportation,

Washington D.C., June 2002

12. De Jaeger R, Gleria M. Prog. Polym. Sci. 1998; 23: 179

13. Chen-Yang YW, Lee HF, Chuan CY. J. Polym. Sci., Polym. Chem. 2000; 38: 972

14. Levchik SV, Camino G, Luda MP, Costa L, Lindsay A, Stevenson D. J. Appl. Polym. Sci. 1998; 67: 461

15. Mathew D, Nair CPR Ninan KN. Polym. Int. 2000; 49: 48

16. Chen-Yang YW, Cheng SJ, Tsai BD. Ind. Eng. Chem. Res. 1991; 30: 1314

17. Emsley J, Hall D. The Chemistry of Phosphorus, Harper and Row: London, 1976, p. 417

18. Barton JM, Chaplin A, Hamerton I, Howlin BJ. Polymer 1999; 40: 5421

19. Gunther H. NMR Spectroscopy, $2^{\text {nd }}$ ed, John Wiley: Chichester, 1995, p. 105 
20. Grigat E, Pütter, R. Chem. Ber. 1964; 97: 3012

21. Cooley JH, Evain EJ. Synthesis 1989: 1

22. Bauer M, Bauer J. Aspects of the kinetics, modelling and simulation of network build-up during cyanate ester cure Chapter 3 in Chemistry and Technology of Cyanate Ester Resins, I. Hamerton (Ed) Blackie Academic and Professional: Glasgow, 1994.

23. Barton JM. The application of differential scanning calorimetry (DSC) to the study of epoxy resin curing reactions in Epoxy Resins and Composites 1 , K.

Dušek (Ed) Adv. Polym. Sci. 1985; 72: 111-154 
synthesis of the monomer and a preliminary study of its thermal properties in binary blends

Ian Hamerton ${ }^{{ }^{1}}$, Simon Glynn ${ }^{1}$, John N. Hay $^{1}$, Mark A. Pullinger ${ }^{1}$ and Stephen J. Shaw ${ }^{2}$

${ }^{1}$ Chemical Sciences Division, Faculty of Health and Medical Sciences, University of Surrey, Guildford, Surrey, GU2 7XH, U.K. ${ }^{2}$ Dstl, Porton Down, Salisbury, Wiltshire, SP4 OJQ, U.K.

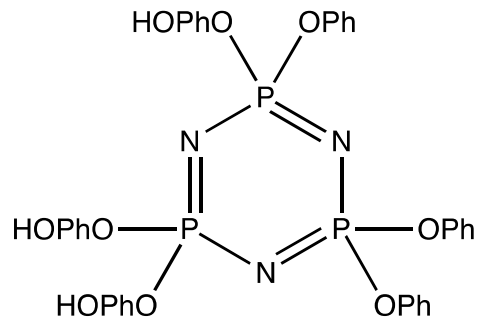

(3)

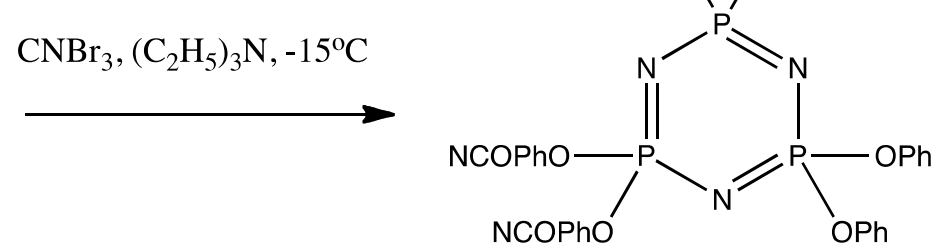

(4) 
Studies of polycyanurates based on phenoxy-substituted cyclic phosphazenes: synthesis of the monomer and a preliminary study of its thermal properties in binary blends

Ian Hamerton ${ }^{1}$, Simon Glynn ${ }^{1}$, John N. Hay ${ }^{1}$, Mark A. Pullinger ${ }^{1}$ and Stephen J. Shaw ${ }^{2}$

${ }^{1}$ Chemical Sciences Division, Faculty of Health and Medical Sciences, University of Surrey, Guildford, Surrey, GU2 7XH, U.K.

${ }^{2}$ Dstl, Porton Down, Salisbury, Wiltshire, SP4 OJQ, U.K.

* Correspondence to: Ian Hamerton, Chemical Sciences Division, Faculty of Health and Medical Sciences, University of Surrey, Guildford, Surrey,

GU2 7XH, U.K. E-mail: i.hamerton@surrey.ac.uk 


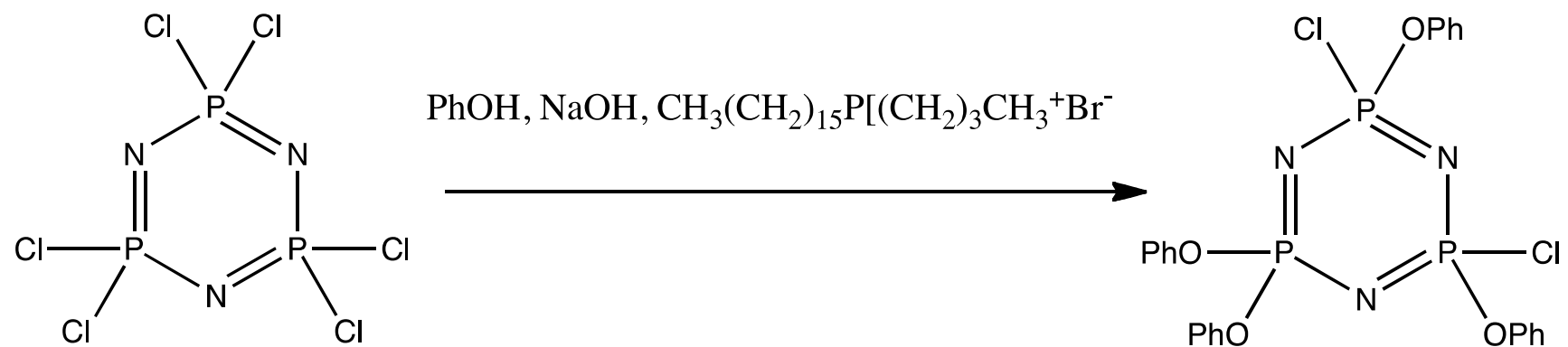

(1)

Scheme 1. Schematic showing the preparation of compound (1) 


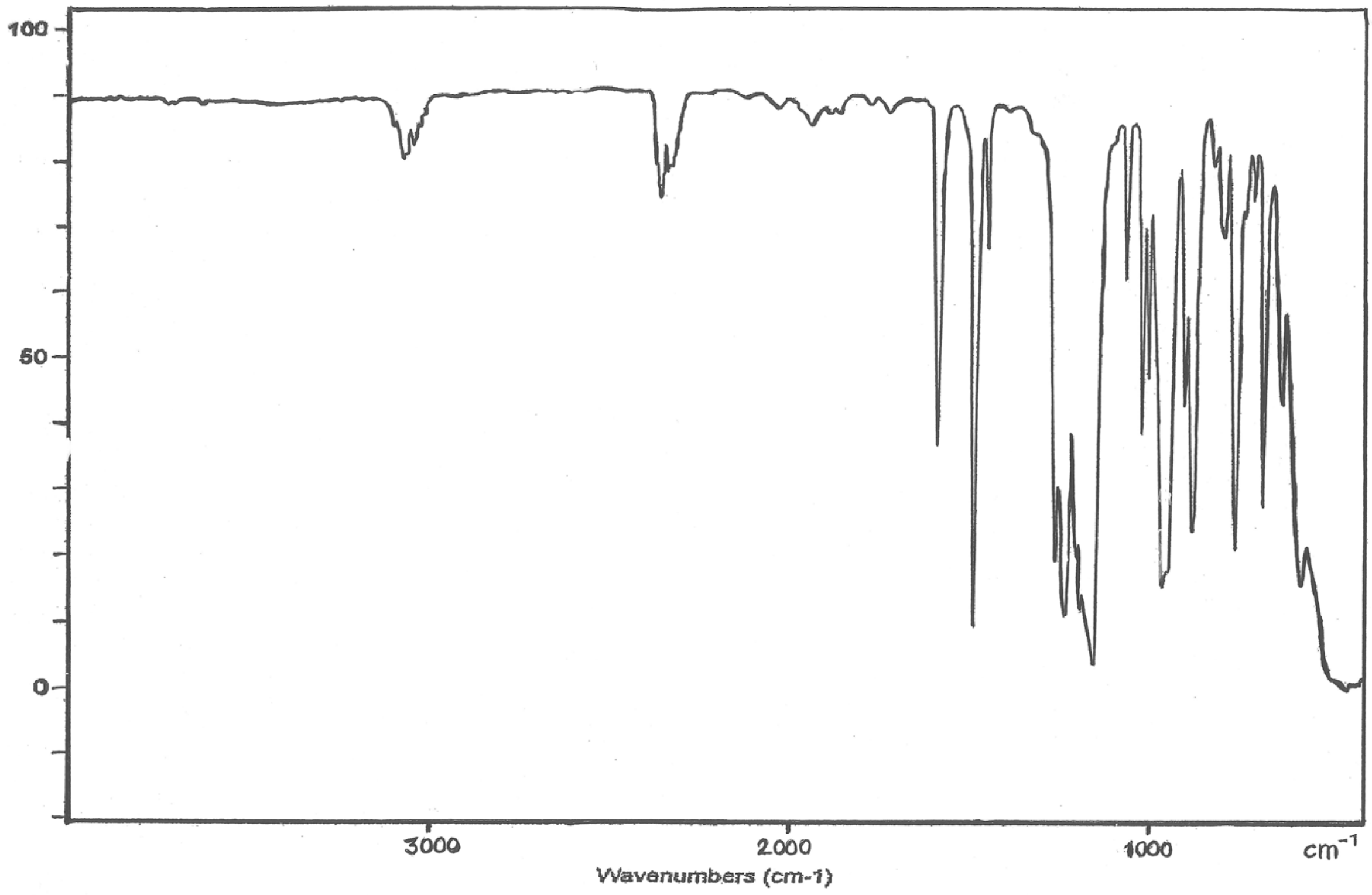

Figure 1. FTIR transmission spectrum of compound (1A) - vertical scale (\%) 


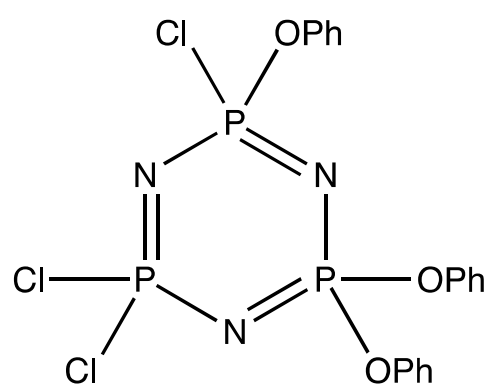

(1A)

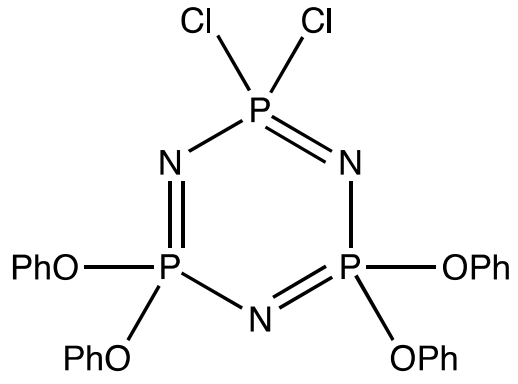

(1B)

Scheme 2. Representative structures present in fractions (1A) and (1B) 


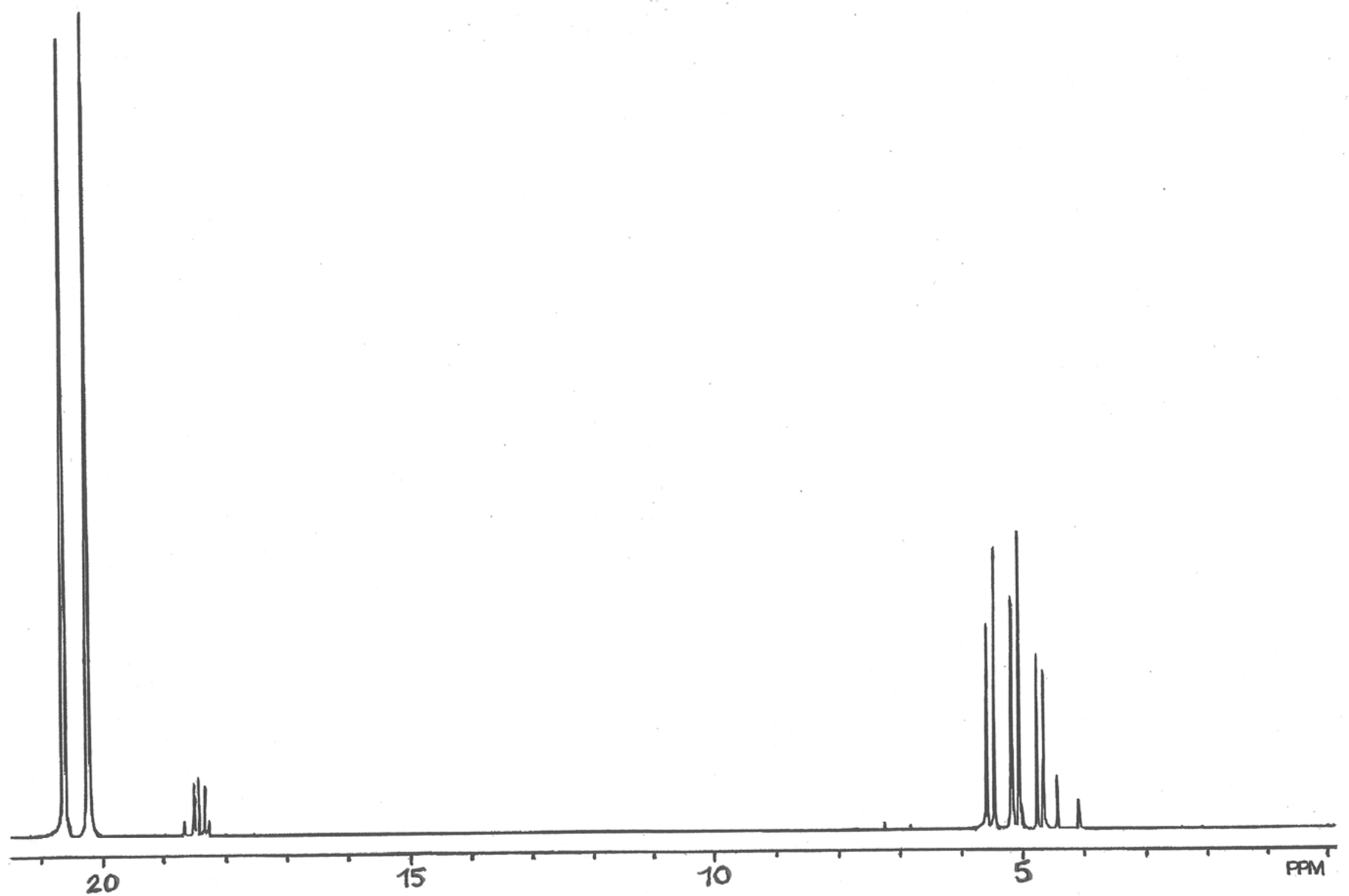

Figure 2. ${ }^{31} \mathrm{P}$ NMR spectrum (in $\mathrm{CDCl}_{3}$ ) of compound (1A) 

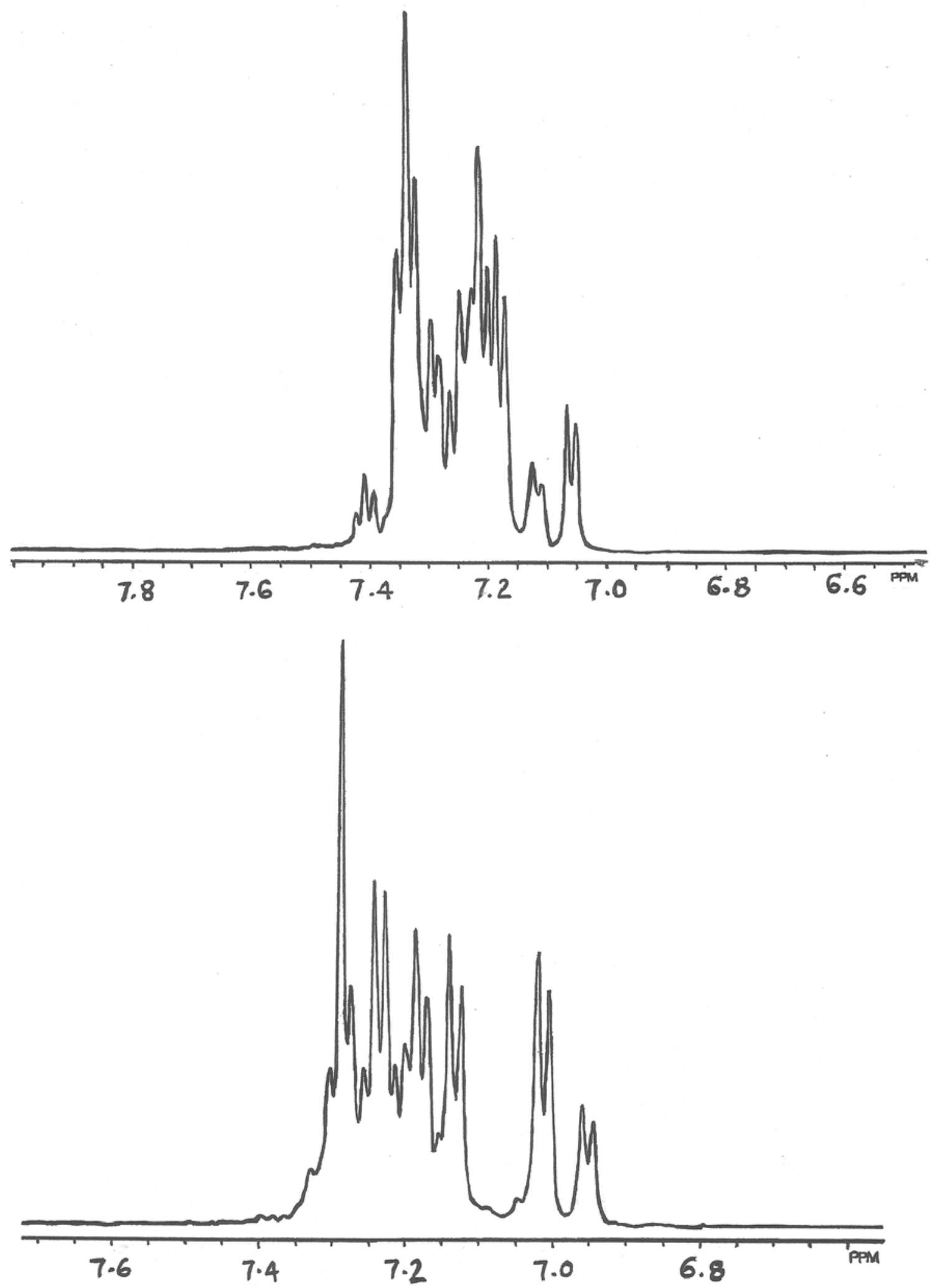

Figure 3. ${ }^{1} \mathrm{H}$ NMR spectra (in $\mathrm{CDCl}_{3}$ ) showing aromatic region of compound (1A) (above) and compound (1B) (below) - note spectra are not plotted on common axes. 


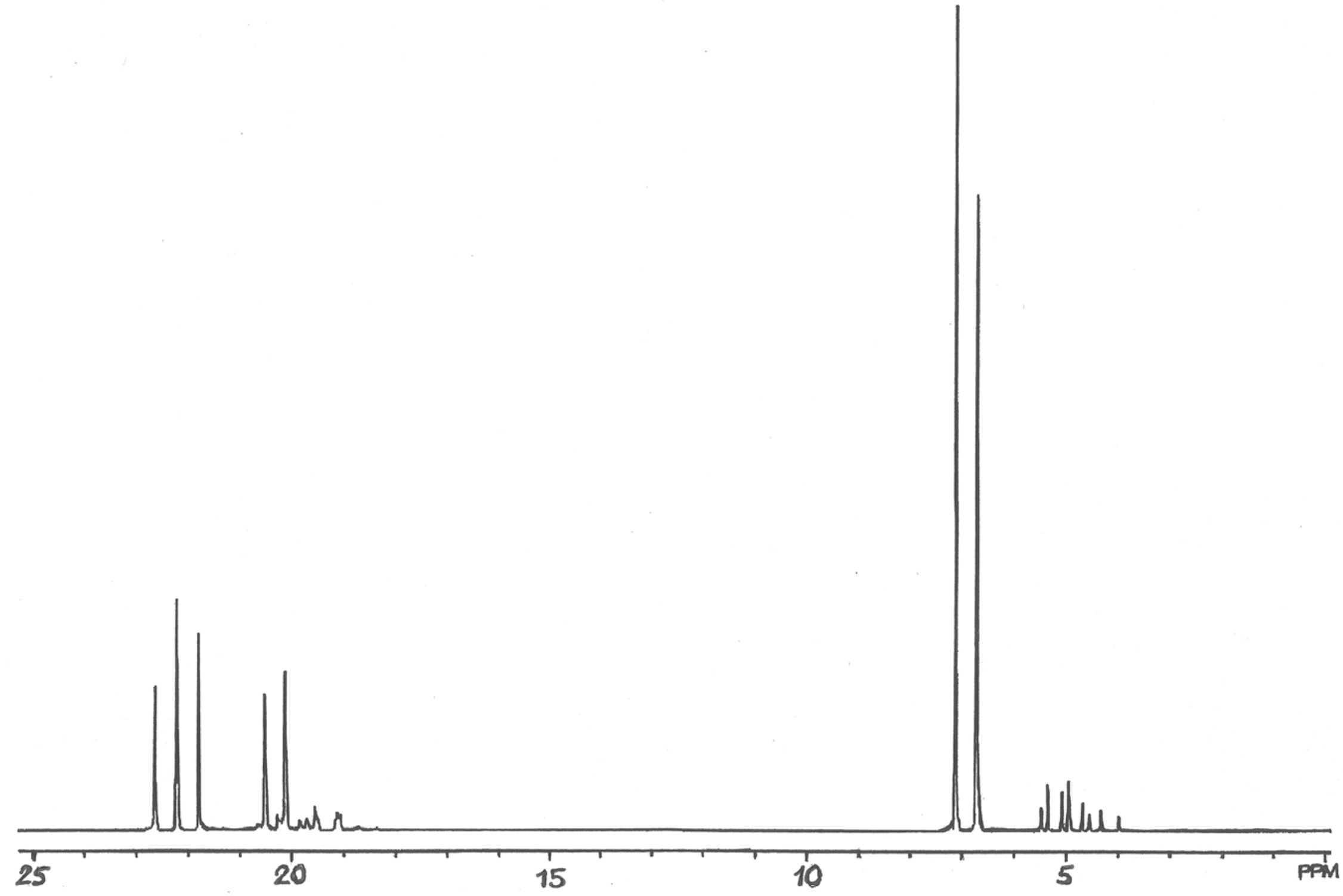

Figure 4. ${ }^{31} \mathrm{P}$ NMR spectrum (in $\mathrm{CDCl}_{3}$ ) of compound (1B) 


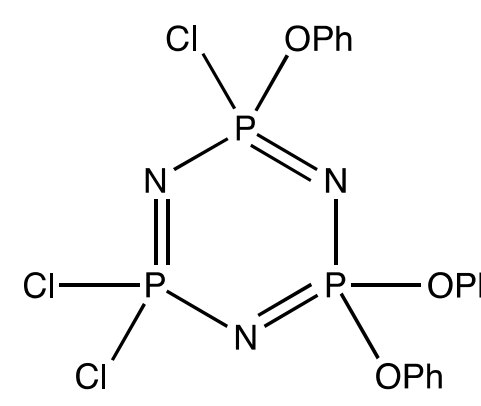

(1A)

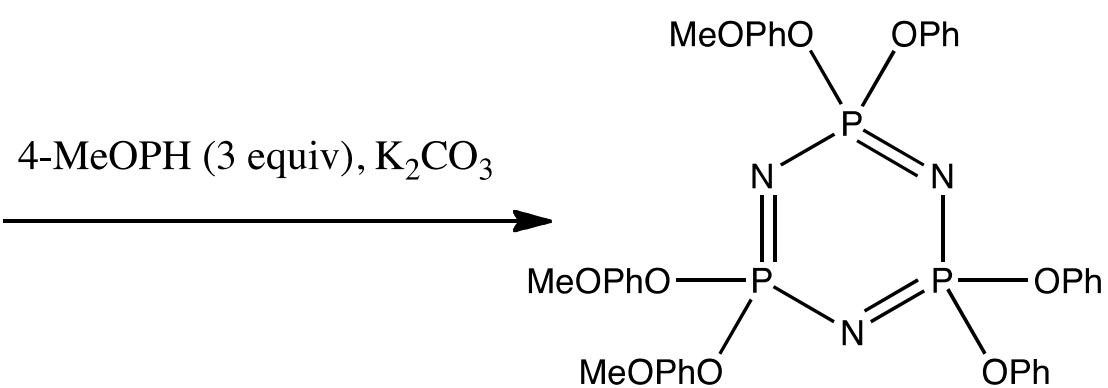

(2)

Scheme 3. Preparation of compound (2) showing the predominant isomer 


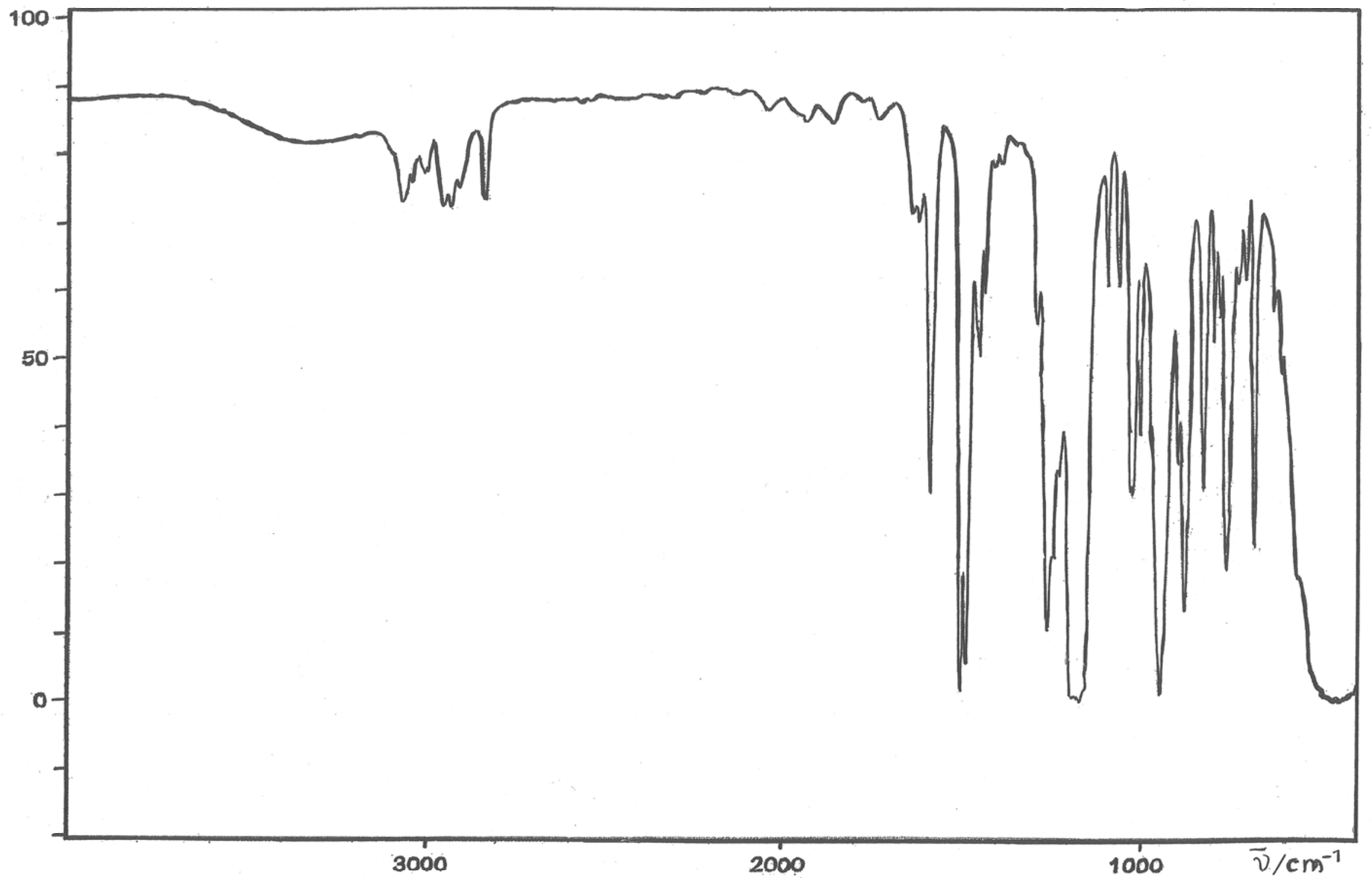

Figure 5. FTIR transmission spectrum (thin film) of compound (2) - vertical scale (\%) 


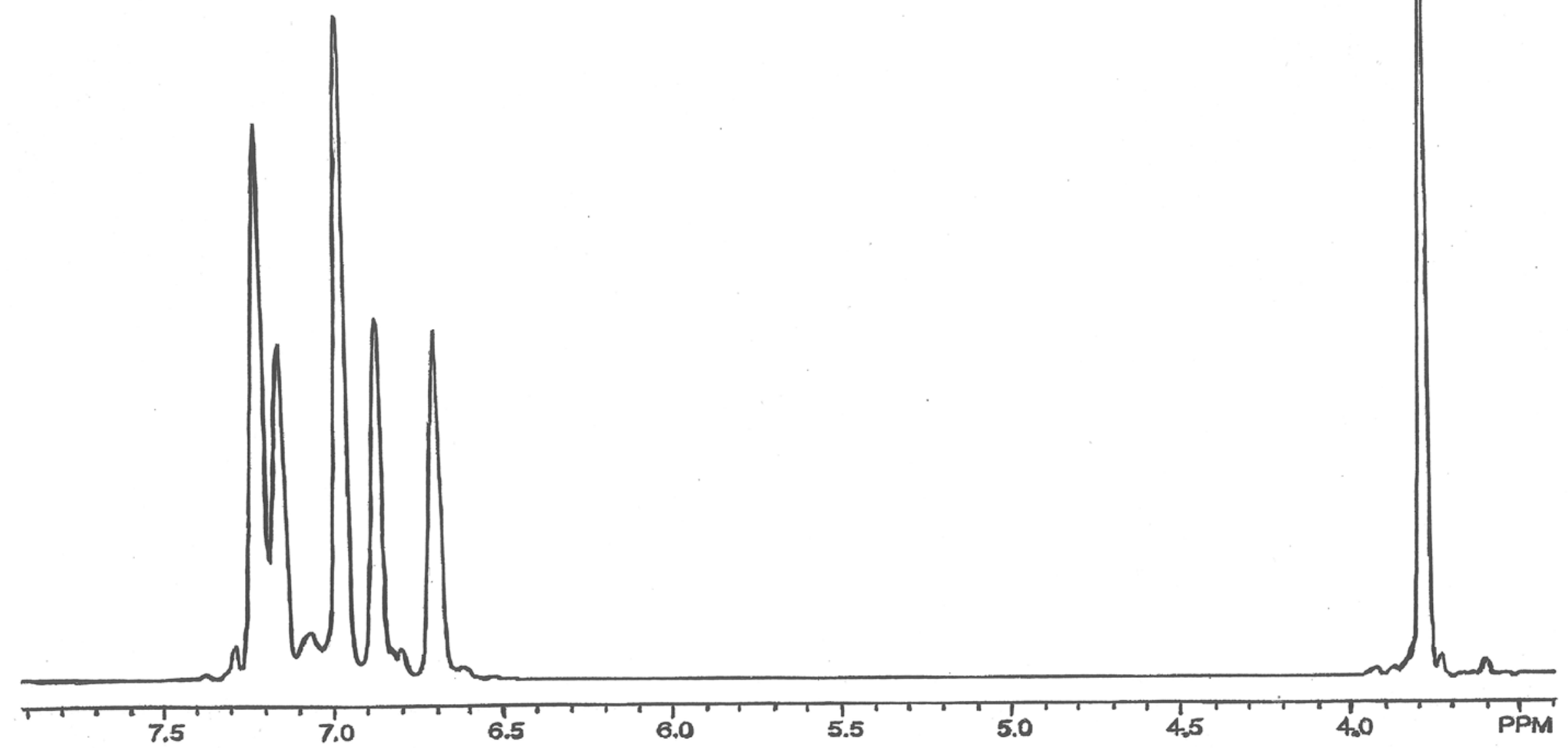

Figure 6. (a) ${ }^{1} \mathrm{H}$ NMR spectrum $\left(\mathrm{CDCl}_{3}\right)$ of compound (2) 


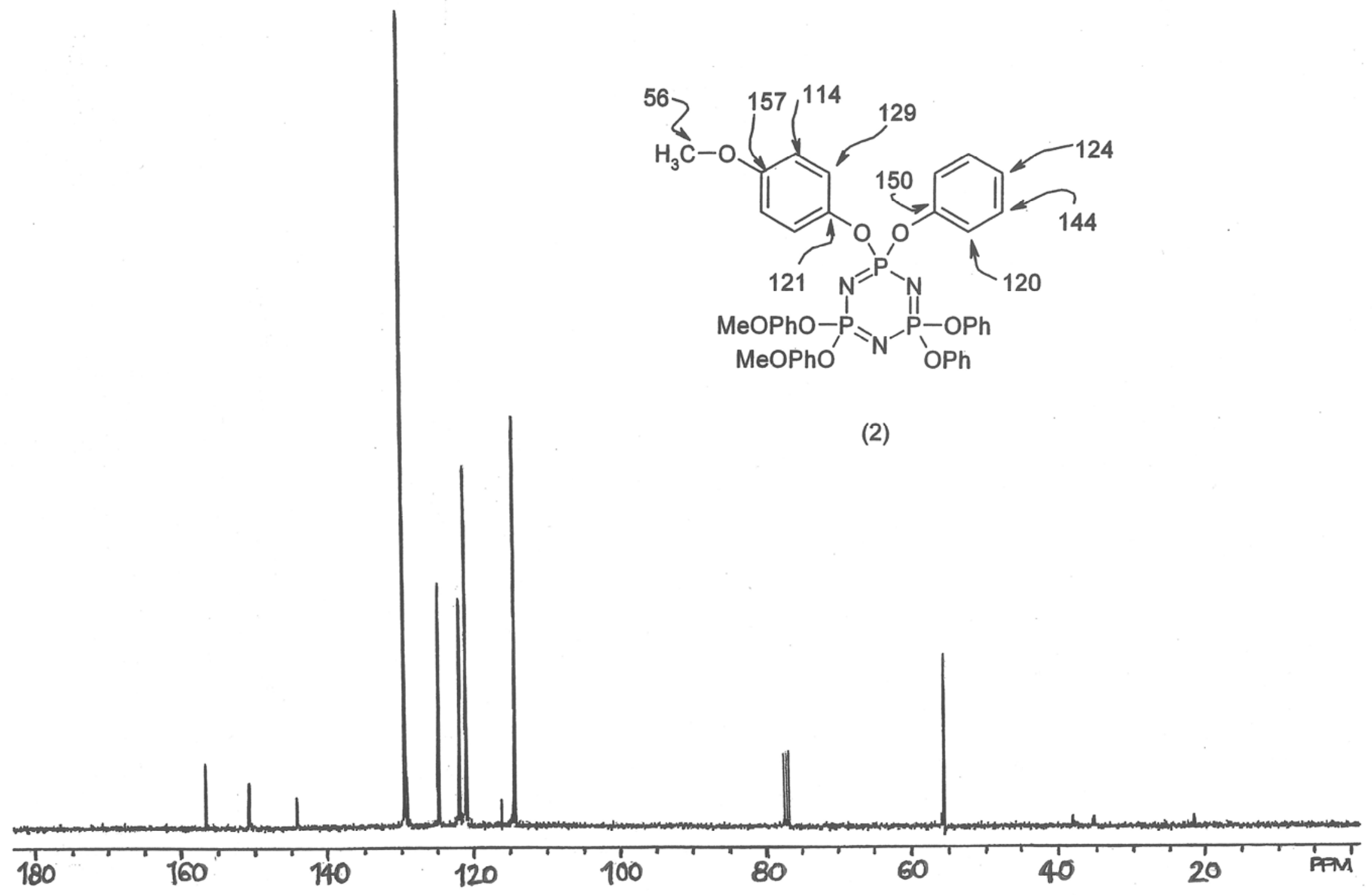

Figure 7. ${ }^{13} \mathrm{C}$ NMR spectrum $\left(\mathrm{CDCl}_{3}\right)$ of compound (2) and proposed assignments 


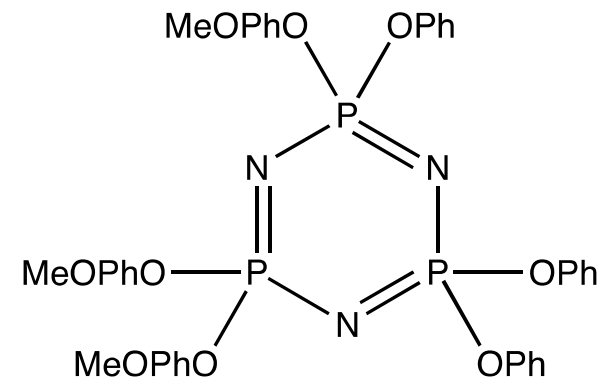

(2)

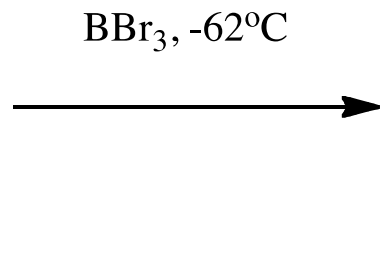

\section{Scheme 4. Preparation of compound (3), showing the predominant isomer}

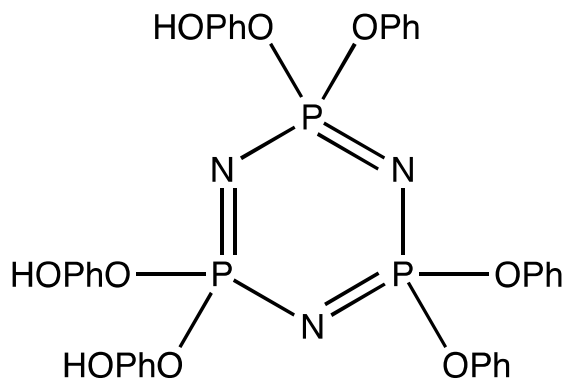

(3) 


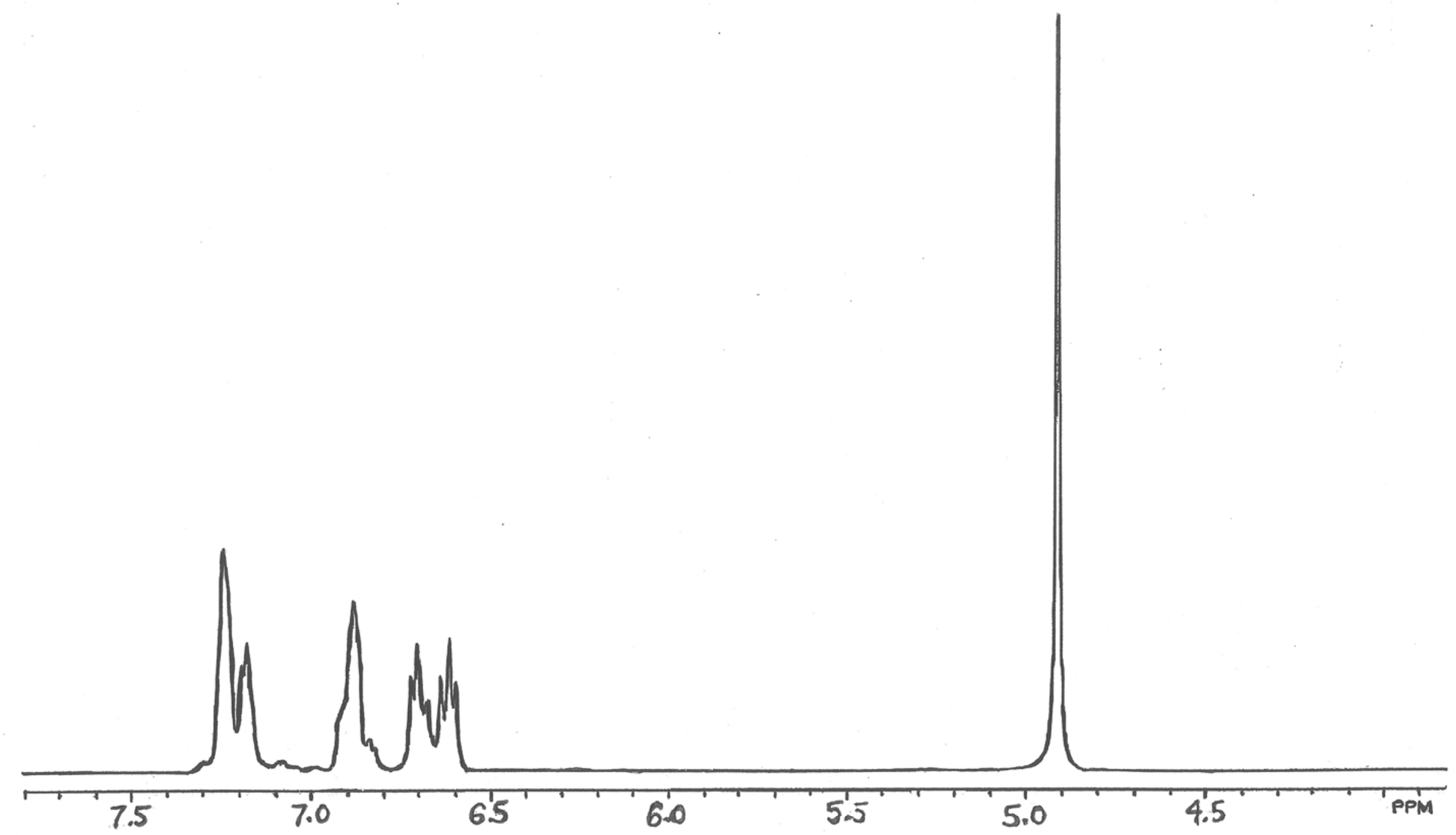

Figure 8. ${ }^{1} \mathrm{H}$ NMR spectrum $\left(\mathrm{CD}_{3} \mathrm{OD}\right)$ of compound (3) 


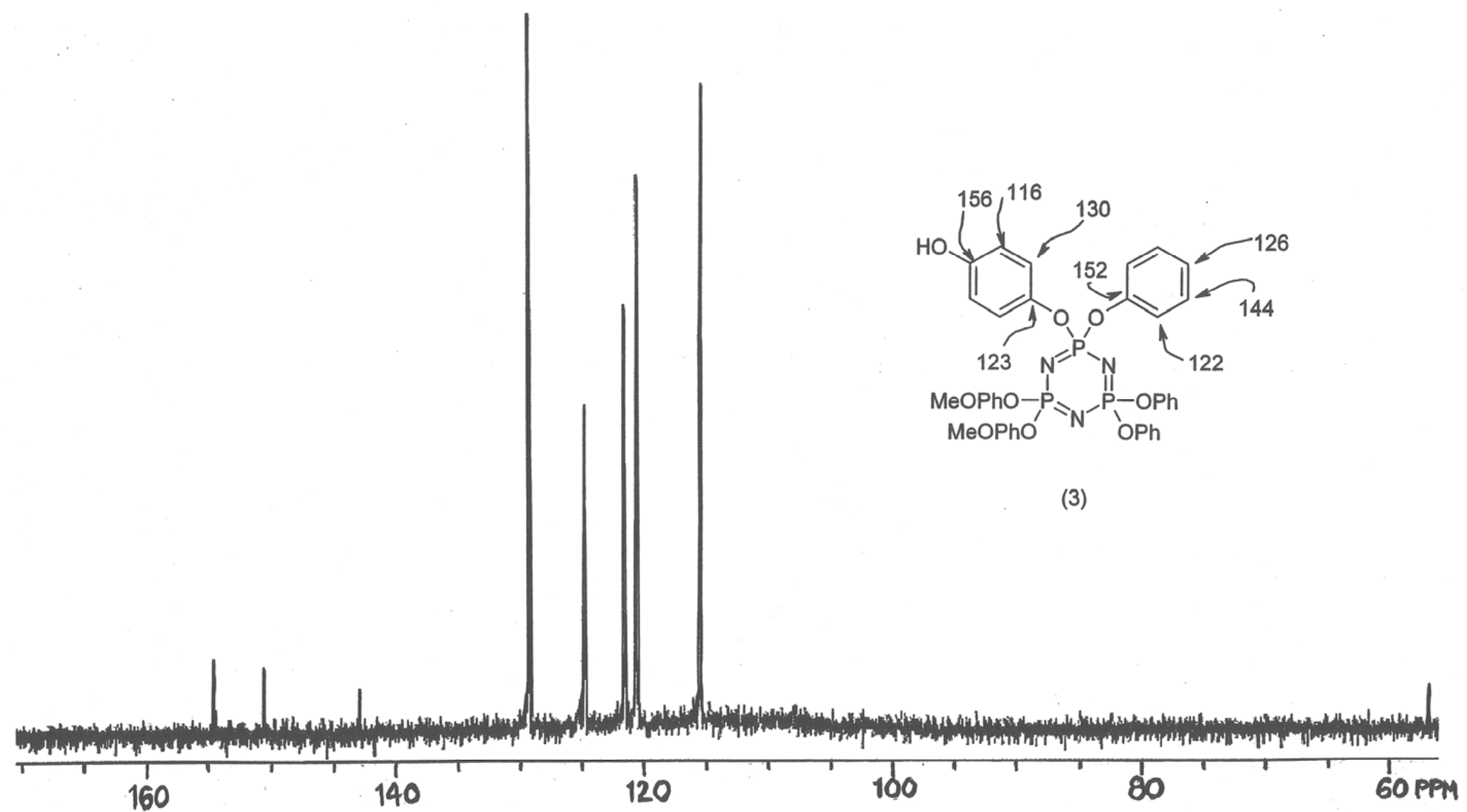

Figure 9. ${ }^{13} \mathrm{C}$ NMR spectrum $\left(\mathrm{CD}_{3} \mathrm{OD}\right)$ of compound (3) and proposed assignments 


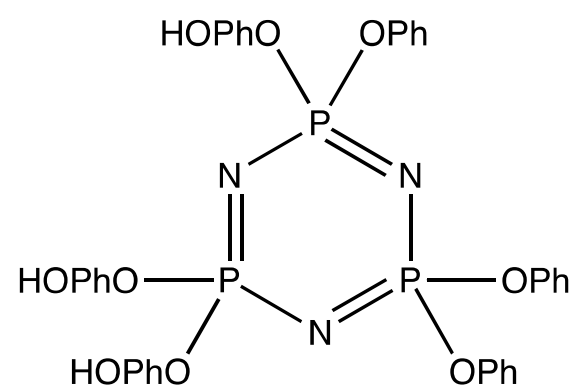

(3)

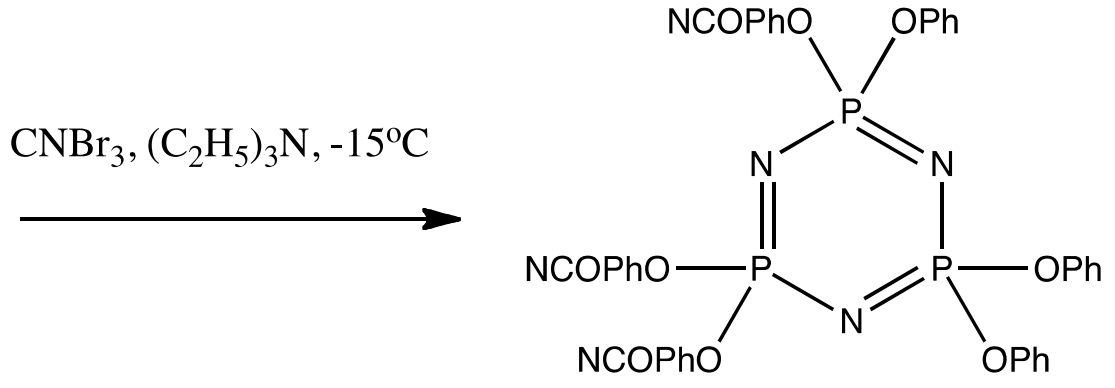

(4)

Scheme 5. Preparation of compound (4), showing the predominant isomer 


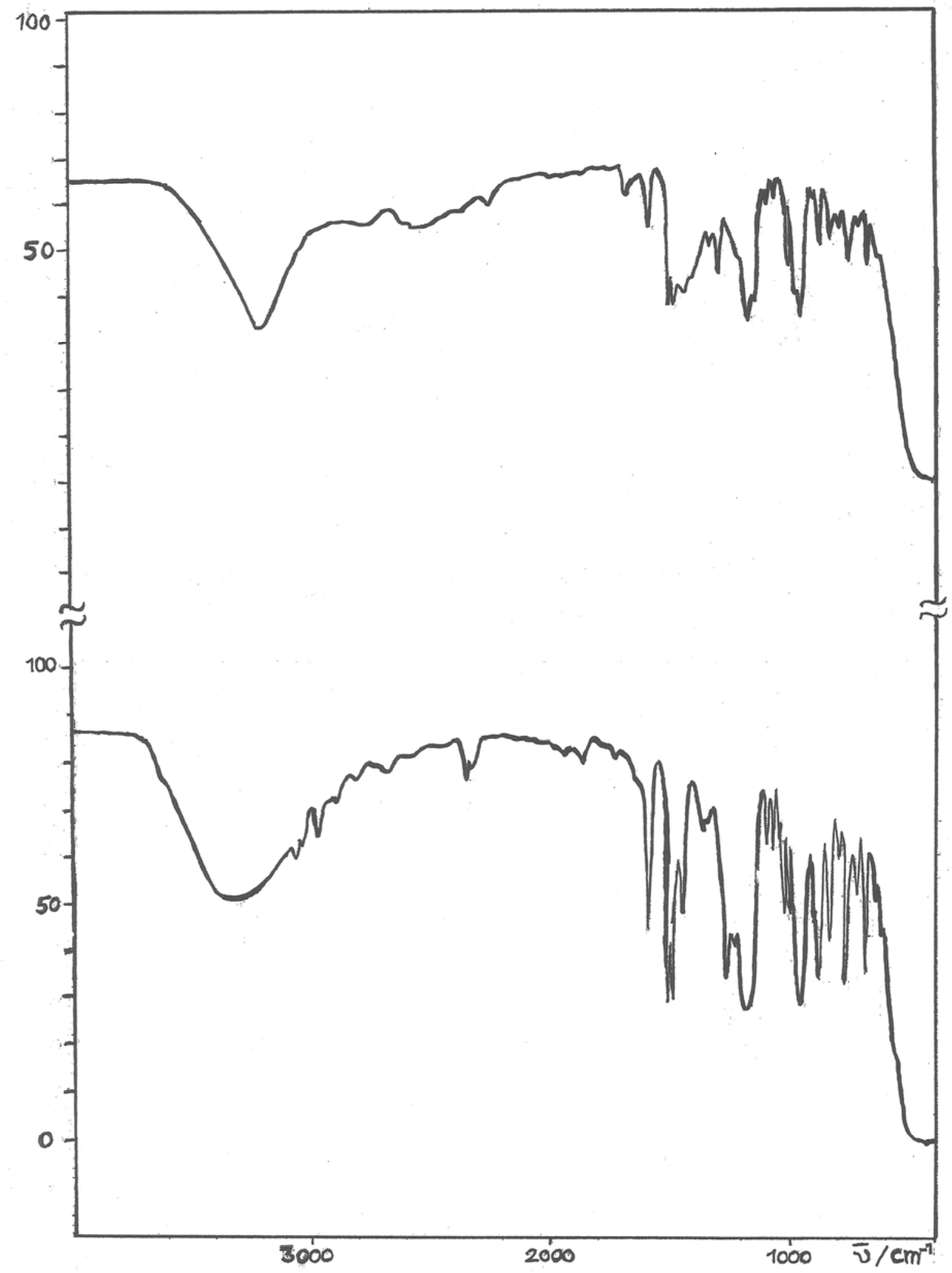

Figure 10. FTIR transmission spectrum (thin film) of crude compound (3) (upper) and the same compound following recrystallisation (lower) - vertical scale (\%) 


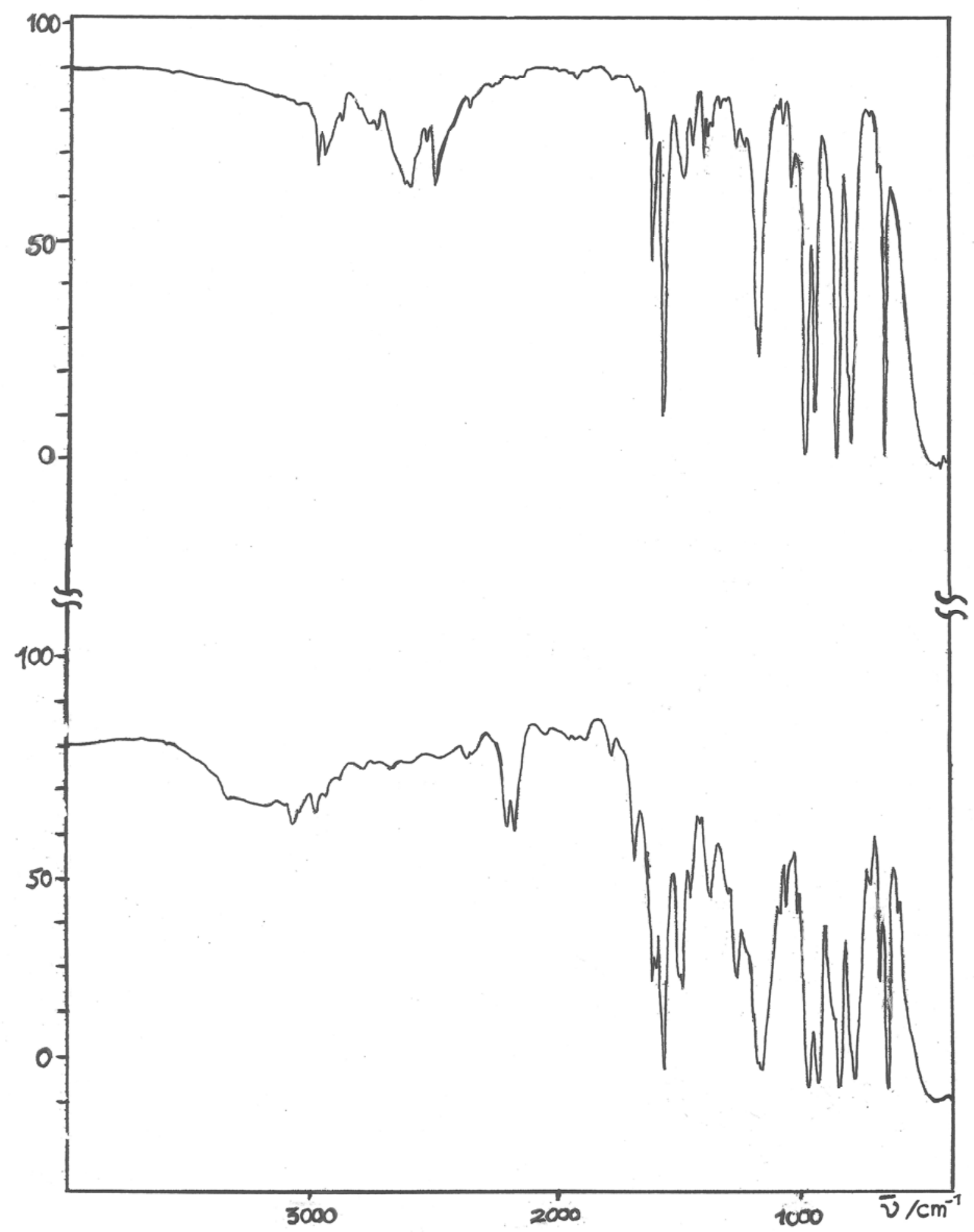

Figure 11. FTIR transmission spectrum (hexachlorobutadiene mull) of crude compound (4) (upper) and the same compound following washing (lower) - vertical scale (\%) 


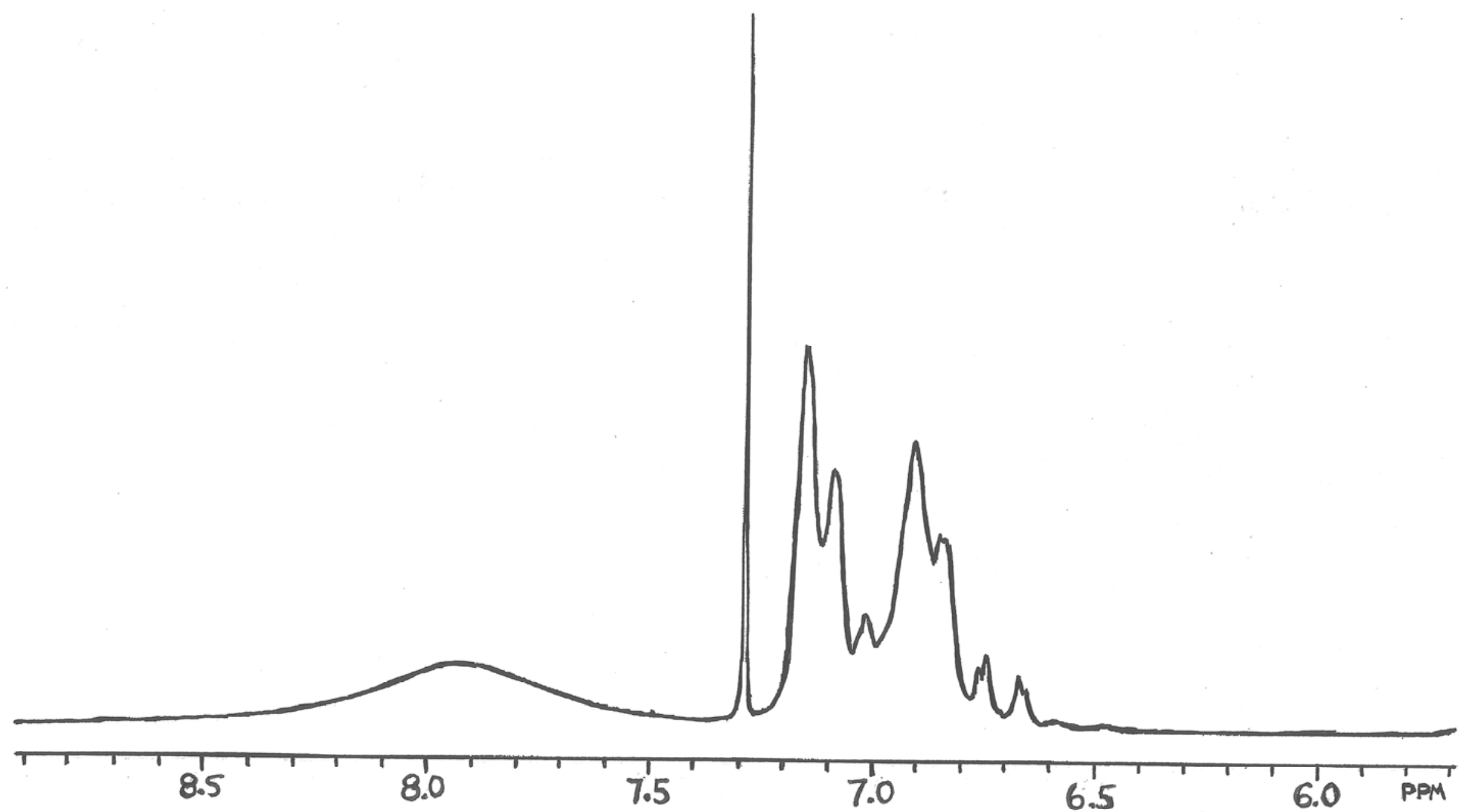

Figure 12. Partial ${ }^{1} \mathrm{H}$ NMR spectrum $\left(\mathrm{CDCl}_{3}\right)$ of crude compound (4) showing labile proton 


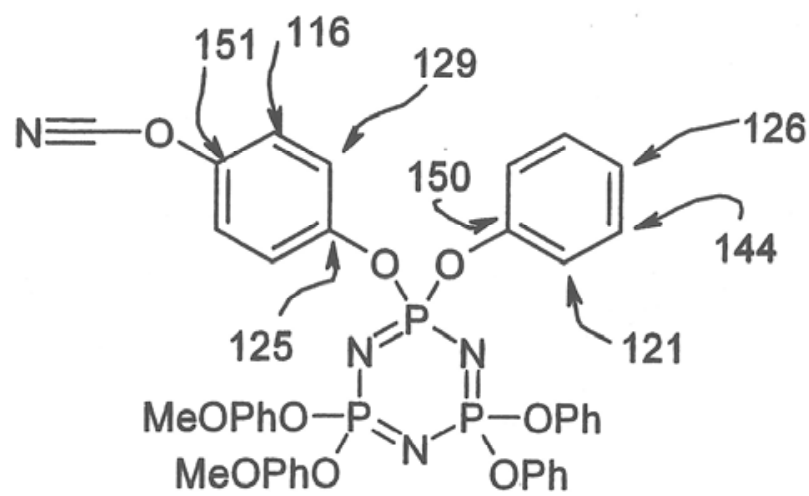

(4)

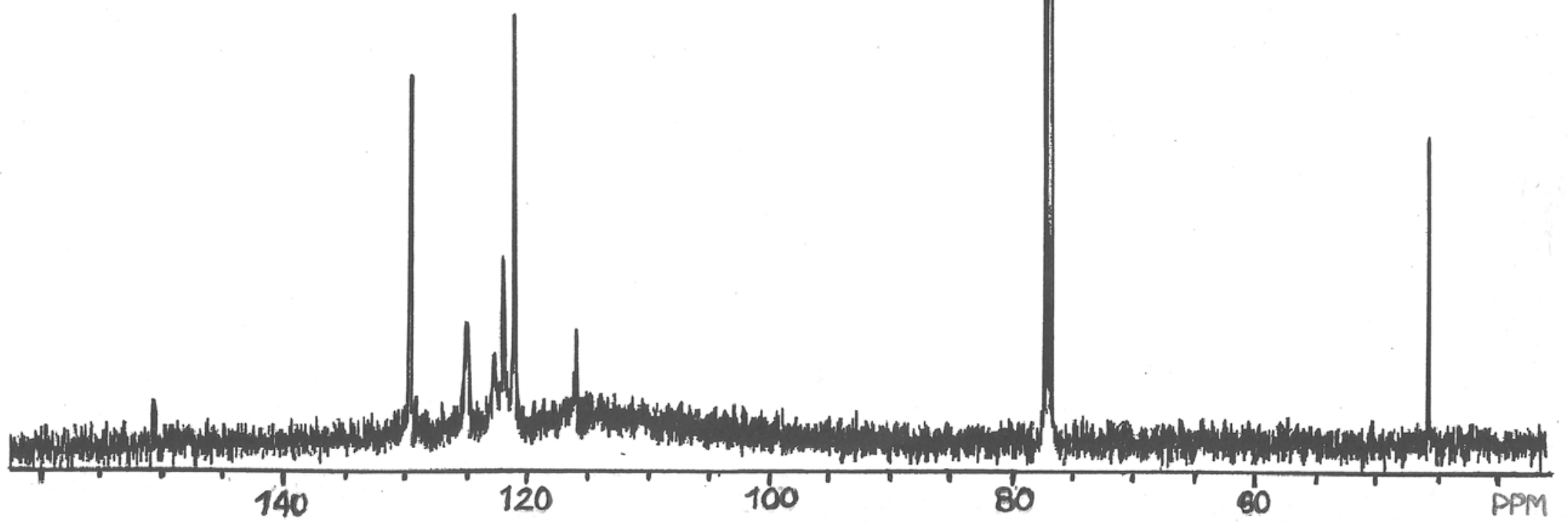

Figure 13. ${ }^{13} \mathrm{C}$ NMR spectrum $\left(\mathrm{CDCl}_{3}\right)$ of crude compound (4) and proposed assignments 


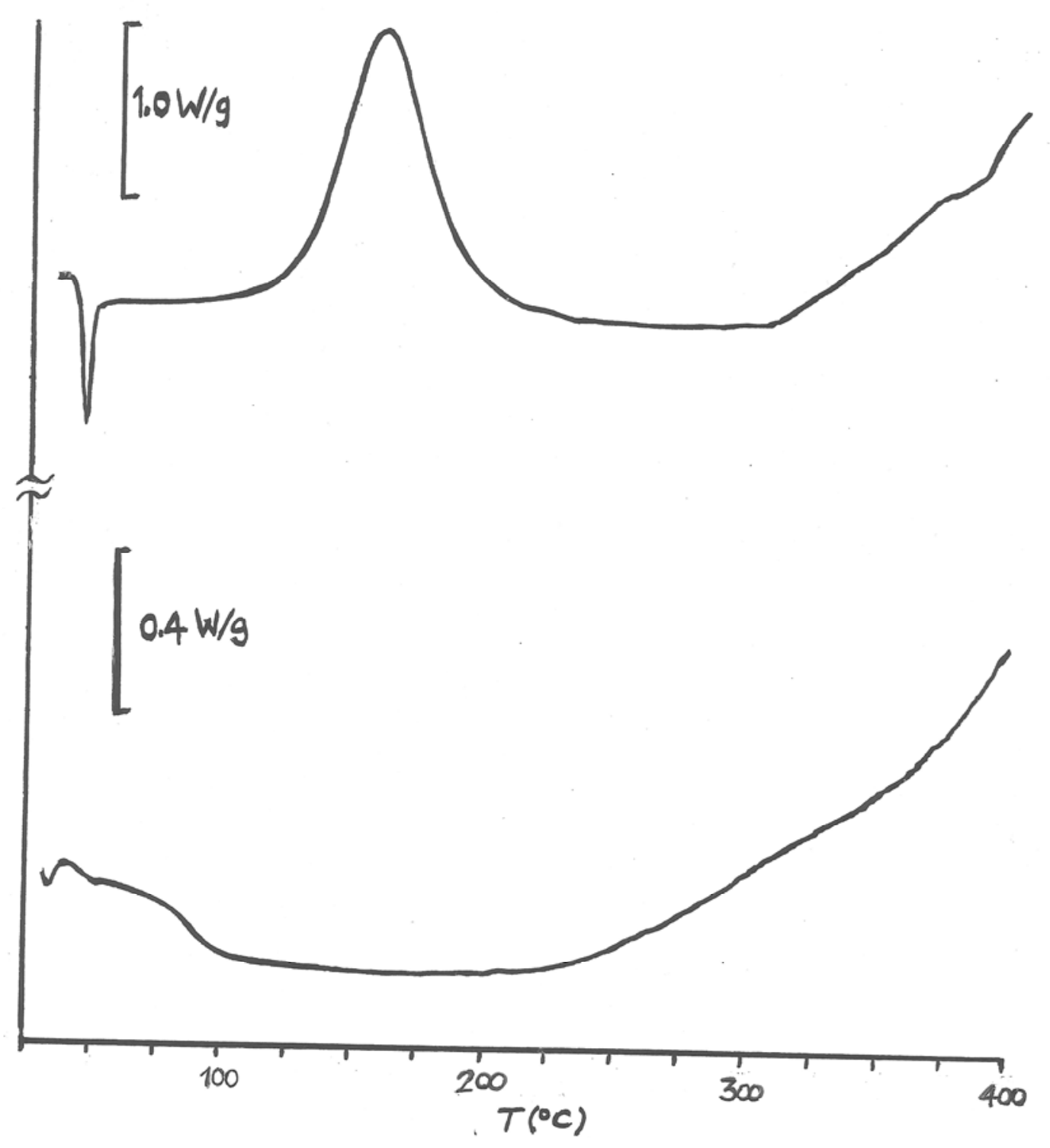

Figure 14. DSC thermogram of compound (4) at $10 \mathrm{~K} \mathrm{~min}^{-1}$ under flowing nitrogen (upper) the rescan is shown below. Exothermic heat flow is show upwards 
Studies of polycyanurates based on phenoxy-substituted cyclic phosphazenes: synthesis of the monomer and a preliminary study of its thermal properties in binary blends

Ian Hamerton ${ }^{{ }^{1}}$, Simon Glynn ${ }^{1}$, John N. Hay ${ }^{1}$, Mark A. Pullinger ${ }^{1}$ and Stephen J. Shaw $^{2}$

${ }^{1}$ Chemical Sciences Division, Faculty of Health and Medical Sciences, University of Surrey, Guildford, Surrey, GU2 7XH, U.K.

${ }^{2} D s t l$, Porton Down, Salisbury, Wiltshire, SP4 OJQ, U.K.

* Correspondence to: Ian Hamerton, Chemical Sciences Division, Faculty of Health and Medical Sciences, University of Surrey, Guildford, Surrey, GU2 7XH, U.K. E-mail: i.hamerton@surrey.ac.uk 
Table 1. Dynamic DSC data for dicyanate monomer (4) as a function of heating rate.

\begin{tabular}{|c|c|c|c|c|c|c|}
\hline \multirow{2}{*}{$\begin{array}{l}\text { Heating } \\
\text { rate } \\
\left(\mathrm{K} \mathrm{min}^{-1}\right)\end{array}$} & \multirow{2}{*}{$\begin{array}{l}\text { m.p. } \\
\left({ }^{\circ} \mathrm{C}\right)\end{array}$} & \multirow{2}{*}{$\begin{array}{l}\mathbf{T}_{\mathbf{g}} \\
\left({ }^{\circ} \mathrm{C}\right)\end{array}$} & \multirow{2}{*}{$\begin{array}{l}\text { Cure } \\
\text { onset }^{\text {a }} \\
\left({ }^{\circ} \mathrm{C}\right)\end{array}$} & \multirow{2}{*}{$\begin{array}{l}\text { Peak } \\
\text { max } \\
\left({ }^{\circ} \mathrm{C}\right)\end{array}$} & \multicolumn{2}{|c|}{$-\Delta \mathbf{H}$ polymerization } \\
\hline & & & & & ( $\mathrm{J} \mathrm{g}^{-1}$ blend $)$ & $\begin{array}{l}\mathrm{kJ} \mathrm{mol}^{-1} \\
(\mathrm{OCN})\end{array}$ \\
\hline 2 & 42 & & 98 & 126 & 33 & 13 \\
\hline 5 & 44 & & 114 & 145 & 86 & 34 \\
\hline 10 & 45 & 160 & 125 & 158 & 96 & 37 \\
\hline 15 & 47 & & 133 & 165 & 82 & 32 \\
\hline 20 & 48 & & 139 & 172 & 97 & 38 \\
\hline
\end{tabular}

${ }^{\mathrm{a}}=$ onset defined as tangent extrapolated from half peak height to baseline. 
Table 2. Arrhenius kinetic parameters for the thermal cure of compound (4) fitted for $n=2$

\begin{tabular}{|c|c|c|}
\hline Scan Rate $\left(\mathrm{K} \mathrm{min}^{-\mathbf{1}}\right)$ & $\mathbf{E}_{\mathbf{a}}\left(\mathrm{kJ} \mathrm{mol}^{-\mathbf{1}}\right)$ & $\mathbf{A}\left(\mathbf{L} \cdot \mathbf{m o l}^{-\mathbf{1}} \cdot \mathbf{s}^{-\mathbf{1}}\right)$ \\
\hline 2 & 144 & $8 \times 10^{17}$ \\
\hline 5 & 150 & $3 \times 10^{18}$ \\
\hline 10 & 124 & $1 \times 10^{15}$ \\
\hline 15 & 151 & $1 \times 10^{18}$ \\
\hline 20 & 147 & $3 \times 10^{17}$ \\
\hline
\end{tabular}


Table 3. Sample blends prepared and analysed in this work

\begin{tabular}{|c|c|c|}
\hline Sample Designation & $(4)$ & AroCy B10 \\
\hline & 10 & 90 \\
\hline $4-10-B 10-90$ & 20 & 80 \\
\hline $4-20-B 10-80$ & 30 & 70 \\
\hline $4-30-B 10-70$ & & \\
\hline
\end{tabular}

AroCy B10 2,2-bis(4-cyanatophenyl)propane

(4)

1,2,3-tris(4-cyanatophenoxy)-,3',5,5-tris-phenoxy-2 $\lambda^{5}, 4 \lambda^{5}, 6 \lambda^{5}-[1,3,5,2,4,6]$-triazatriphosphinine 
Table 4. Dynamic DSC data for binary blends containing dicyanate monomer (4) as a function of heating rate.

\begin{tabular}{|c|c|c|c|c|c|}
\hline Sample & $\begin{array}{l}\text { Heating } \\
\text { rate } \\
\left(\mathrm{K} \mathrm{min}{ }^{-1}\right)\end{array}$ & $\begin{array}{l}\text { m.p. } \\
\left({ }^{\circ} \mathrm{C}\right)\end{array}$ & $\begin{array}{l}\mathbf{T}_{\mathbf{g}} \\
\left({ }^{\circ} \mathrm{C}\right)\end{array}$ & $\begin{array}{l}\text { Cure } \\
\text { onset }^{a} \\
\left({ }^{\circ} \mathrm{C}\right)\end{array}$ & $\begin{array}{l}\text { Peak } \\
\text { max } \\
\left({ }^{\circ} \mathrm{C}\right)\end{array}$ \\
\hline AroCy B10 & 10 & 82 & 230 & ca. $90^{\mathrm{b}}$ & 126 \\
\hline 4-10-B10-90 & 10 & 79 & 163 & ca. $90^{\mathrm{b}}$ & 135 \\
\hline $4-20-B 10-80$ & 10 & 78 & 190 & ca. $88^{\mathrm{b}}$ & 135 \\
\hline 4-30-B10-70 & 10 & 77 & 166 & ca. $88^{\mathrm{b}}$ & 136 \\
\hline
\end{tabular}

${ }^{\mathrm{a}}=$ onset defined as tangent extrapolated from half peak height to baseline.

$\mathrm{b}=$ onset of polymerization obscured by melting endotherm of monomer.

AroCy B10 = 2,2-bis(4-cyanatophenyl)propane 
Table 5. TG data for the thermal/thermo-oxidative degradation of the cured homopolymer and copolymers

\begin{tabular}{|c|c|c|c|c|c|c|c|c|c|c|c|}
\hline & \multirow[t]{2}{*}{ Atmosphere } & \multicolumn{10}{|c|}{ Temperature $\left({ }^{\circ} \mathrm{C}\right)$ for a given mass loss } \\
\hline & & $5 \%$ & $10 \%$ & $15 \%$ & $20 \%$ & $30 \%$ & $40 \%$ & $50 \%$ & $60 \%$ & $80 \%$ & $100 \%$ \\
\hline (4) & nitrogen & 366 & 396 & 421 & 456 & 501 & 551 & 816 & 891 & $>1000$ & $\mathrm{~N} / \mathrm{A}$ \\
\hline (4) & air & 381 & 418 & 453 & 481 & 519 & 652 & 710 & 732 & 780 & N/A \\
\hline AroCy B10 & air & 370 & 405 & 420 & 425 & 430 & 460 & 540 & 560 & 580 & N/A \\
\hline 4-B10-90 & air & 295 & 325 & 360 & 380 & 410 & 425 & 450 & 510 & 575 & N/A \\
\hline 4-B10-80 & air & 225 & 280 & 310 & 340 & 400 & 425 & 475 & 540 & 600 & N/A \\
\hline 4-B10-70 & air & 230 & 270 & 280 & 290 & 305 & 315 & 380 & 430 & 660 & N/A \\
\hline
\end{tabular}

N/A samples exhibited some char yield at conclusion of experiment $(<3 \%)$

AroCy B10 2,2-bis(4-cyanatophenyl)propane 
